This item was submitted to Loughborough's Research Repository by the author.

Items in Figshare are protected by copyright, with all rights reserved, unless otherwise indicated.

\title{
The effects of news events on market contagion: evidence from the 2007- 2009 financial crisis
}

PLEASE CITE THE PUBLISHED VERSION

http://dx.doi.org/10.1016/j.ribaf.2014.03.003

\section{PUBLISHER}

Crown Copyright @ Published by Elsevier B.V.

VERSION

AM (Accepted Manuscript)

\section{PUBLISHER STATEMENT}

This work is made available according to the conditions of the Creative Commons Attribution-NonCommercialNoDerivatives 4.0 International (CC BY-NC-ND 4.0) licence. Full details of this licence are available at: https://creativecommons.org/licenses/by-nc-nd/4.0/

\section{LICENCE}

CC BY-NC-ND 4.0

\section{REPOSITORY RECORD}

Chevapatrakul, Thanaset, and Kai-Hong Tee. 2019. "The Effects of News Events on Market Contagion: Evidence from the 2007-2009 Financial Crisis”. figshare. https://hdl.handle.net/2134/17071. 


\section{The Effects of News Events on Market Contagion: Evidence from the 2007-2009 Financial Crisis}

Thanaset Chevapatrakul and Kai-Hong Tee**

January 2014

${ }^{*}$ Corresponding author. Kai-Hong Tee (email: K.Tee@lboro.ac.uk) is a Senior Lecturer in Finance in School of Business and Economics at Loughborough University. Thanaset Chevapatrakul (email: Thanaset.Chevapatrakul@nottingham.ac.uk) is a Lecturer in Finance at Nottingham University Business School. 


\section{Introduction}

The Global Financial Crisis began in 2007 when the subprime mortgage crisis originated in the US spread rapidly to most financial markets around the globe. This resulted in global stock markets experiencing substantial fall in asset prices and entered a period of high volatility. Major banks and financial institutions also faced serious liquidity problems while governments around the world attempted to coordinate efforts to provide financial rescue.

The 2007 subprime mortgage crisis eventually lead to a global recession. Mishkin (2011) discusses both the crisis and global recession. He terms the first phase as "The Subprime Mortgage Crisis" that began when the French bank BNP Paribas suspended redemption of shares held in some of its money market funds. He carries on to explain that a boom in the US housing prices, which peaked at around 2005, started to decline. Mortgage-backed securities (MBS) - in many cases, securities based on subprime residential mortgages divided into more senior claims that were supposedly safe and junior claims that were recognized to be risky - began to experience huge losses as a consequence. What developed in late 2007 and into 2008 was a series of runs on financial institutions with the collapse of Bear Stearns in March 2008 as one such example.

Mishkin (2011) terms the global recession as the second phase which began with the collapse of Lehman Brothers. The fourth-largest investment bank by asset size with over $\$ 600$ billion in assets and 25,000 employees filed for bankruptcy on $15^{\text {th }}$ September 2008. It is considered to be the largest bankruptcy filing in US history. Mishkin (2011) argues that although the Lehman bankruptcy led to a large increase in uncertainty and a wave of distressed selling of securities that caused a collapse in asset prices and a drying up of liquidity, three major events following the collapse of Lehman Brothers potentially caused the subprime crisis to spread globally. These events are (i) the collapse of AIG on $16^{\text {th }}$ September 2008; (ii) the run on the Reserve Primary Fund on the same day; and (iii) the struggle to get the Troubled Asset Relief Plan (TARP) approved by Congress over the following couple of weeks.

Mishkin (2011) discusses the links between Financial Crisis to recession, providing evidence showing that GDP growth in the US economy had slowed down in the third quarter of 2008, falling at -1.3 percent per annum. But it was in the fourth quarter of 2008 that the recession that started in December 2007 became the worst economic contraction in the United States since World War 
II. Real US GDP contracted sharply in the fourth quarter of 2008 and the first quarter of 2009, declining at annual rates of -5.4 and -6.4 percent, respectively. The unemployment rate skyrocketed, exceeding 10 percent by October 2009. A worldwide recession later ensued, with the world economic growth rate falling at an annual rate of -6.4 percent in the fourth quarter of 2008 and -7.3 percent in the first quarter of 2009.

Unlike past crises, such as the 1997 Asian financial crisis, the 1998 Russian crisis, and the 1999 Brazilian crisis, the global financial crisis of 2008 was originated from the largest and most influential economy, the US. This crisis seemed to trigger a prolonged worldwide fear of contagion and cause a fundamental change in the correlations among international markets, including both developed and emerging markets, which eventually lead to a global recession as research from Cheung et al. (2010) suggest. In this paper, we aim to study the effects of this crisis by analysing the potential contagion in the stock markets. Our aim is to investigate whether major news events related to the crisis, reported during the period, had such an effect. We track the news events, in both the UK and the US, during the credit crisis using the Global Recession Timeline which covers the main events taking place in the first and second stages of the credit crisis as discussed in Mishkin (2011). Table 1 lists the major news events covered in the timeline. In addition to the effects of news events, we also include market sentiments and market volatility in our study. Our model adds two control variables:

(i) VIX which we use as a proxy for market sentiments; and (ii) the conditional volatility, estimated using a bivariate GARCH technique to capture the spillover effects between markets.

We organise the paper as follows. Section 2 reviews relevant literature. Section 3 describes the data used in this study while the statistical methodology is explained in Section 4. We present and discuss our estimation results in Section 5. Finally, Section 6 concludes.

\section{Literature Review}

This section reviews the literature and discusses the use of contagion measures in research. We also discuss the use of correlation and coexceedance in the literature as well as the application of coexceedance to detect contagion using the quantile regression. 


\subsection{Correlations as Contagion Measures}

Correlations have long been used as a measure of contagion academic literature. However, there have also been discussions on the limitation of using correlation for such purpos. Dungey et al. (2005), for example, provide a review on the use of methodology related to contagion measures, which is popularised by Forbes and Rigobon (2002). Compared to Forbes and Rigobon (2002), Dungey et al. (2005) discusses the work of Eichengreen et al. (1995), Eichengreen et al. (1996) and Bae et al. (2003), pointing out that when evaluating extent of contagion, these research papers differ in their approaches to separate the crisis from the non-crisis periods, which affect the choice of methodology employed. For Forbes and Rigobon (2002), the determination of the crisis period is a priori. They test if correlation changes between the crisis and non-crisis periods. Dungey et al. (2005) argue that if asset returns vary with no change to the fundamental relationship between assets returns in the two markets - which result in the correlations of returns in crisis period being higher than that of the non-crisis period - then the approach gives a false appearance of contagion. To adjust for this bias, Dungey et al. (2005) report that Forbes and Rigobon (2002) modify the asset return correlations by scaling them with a nonlinear function of the percentage change in volatility in the asset return of the source country, considering both the crisis and the non-crisis periods. They provide a prescriptive procedure to correct for the bias in the correlation measure, showing that using the unmodified correlation measure to quantify contagion or interdepdence may be inappropriate.

\subsection{Coexceedance as Contagion Measures}

Dungey et al. (2005) also discuss Bae et al. (2003) who define quantile-based threshold to separate the occurrences of extreme returns from non-extreme returns. In this case, co-exceedances exist when returns of the underlying assets follow the same pattern as that of the threshold. In Bae et al. (2003), they first define an extreme return — or an exceedance — as a return that lies below (above) the $5^{\text {th }}\left(95^{\text {th }}\right)$ quantile of the marginal return distribution. Building upon the concept of exceedance, Bae et al. (2003) introduce a measure to assess the joint occurrences of large or small returns: a coexceedance. They define coexceedances as the joint occurrences of $i$ exceedances of negative (positive) returns on a particular day — in other words, the number of $i$ units of joint negative (positive) returns. To determine whether there are more frequent joint occurrences of large 
absolute value returns than expected, Bae et al. (2003) validate the outcomes using Monte Carlo simulations of the joint returns generating processes of international stock market returns with different assumptions about their structures. To investigate the extent to which coexceedances can be used to assess contagions, they develop an econometric model of the joint occurrences of large absolute value returns using multinomial logistic regression - a methodology frequently used in epidemiology research on contagious diseases in which answer can be provided on the effect of the contagion of diseases (Hosmer and Lemeshow, 1989).

\subsubsection{Coexceedance and Asymptotic Dependency Properties of Asset Returns}

Apart from Bae et al. (2003) who adopt the coexceedance measure as an alternative to the correlation measure, existing literature also investigates the asymptotic dependency properties of assets' returns and how it contributes to contagion. One such example is Chan-Lau et al. (2004) who assess the extent of contagion between two underlying markets using patterns and behaviours of coexceedances. They claim that such an approach is often related to the extreme value theory (EVT) which captures the belief of most observers in the private sectors and policymakers that large shocks transmit across financial markets differently from small shocks. They argue that measuring contagion, therefore, requires a determination of the asymptotic dependence class of the series analysed and propose the use of an extremal dependence measure, first documented in Poon et al. (2004). Asymptotic dependence structures can be used to measure different degrees of dependency. Two dependent structures occur when both underlying time series approach their upper or lower limit. As one variable tends to the upper (lower) limit, the probability of the other variable approaching its upper (lower) limit goes to zero for asymptotically independent random variables, but to a nonzero limit for asymptotically dependent variables. This implies that a joint occurrence of extreme values is unlikely for asymptotically independent variables.

Chan-Lau et al. (2004) suggest that such a methodological framework of extremal dependence measures can be measured along two dimensions. The first dimension is linked to changes in the asymptotic properties of the joint tail distribution of equity returns. Contagion is stronger between two countries if the return series are asymptotically dependent: realisations of extreme returns in both countries are likely to occur simultaneously. Therefore, two countries with asymptotically independent joint tail distribution will experience increasing contagion if the joint tail distribution 
becomes asymptotically dependent. Chan-Lau et al. (2004) also observe that an increase in the number of country-pair returns exhibiting asymptotically dependence suggests increasing contagion worldwide as structural changes in the transmission mechanism lead to changes in the asymptotic properties of the joint tail distribution. The second dimension, as also discussed in Chan-Lau et al. (2004), is associated with changes in the dependent measure when the type of asymptotic tail property remains unchanged. In this case, an increase in contagion between two countries is reflected in an increase in the dependence measure rather than changes in the joint tail distribution pattern.

The original framework of extremal dependence measure in Poon et al. (2004), however, focuses more on the evaluation of the assumption made about the asymptotic dependence of the two return distributions while the impact it has on the estimation of portfolio risk is analysed. To do this, a two-asset portfolio is formed to show the consequence of assuming asymptotic dependence when asset returns are asymptotically independent. The probability of the largest possible portfolio losses is evaluated using (i) a Monte Carlo simulation that assumes a distributional pattern following a dependence structure with a specified marginal distribution based on a Generalised Pareto distribution (GPD) and (ii) a simulation of the Gaussian dependence structures based on a bivariate extreme value distribution with logistic dependence structures, which accounts for the asymptotic dependence or independence of the two variables underlying the portfolio. ${ }^{1}$ Poon et al. (2004) suggest that the concept of extremal dependence structure is related to the concept of copula. Their paper subsequently shows that Gaussian copula corresponds to the case of asymptotic independence while a logistic copula corresponds to the case of asymptotic dependence.

Based on copula model, Busetti and Harvey (2011) investigate if dependency between assets' returns change over time. They first denote $\tau^{\text {th }}$ quantile as $\zeta(\tau)$. The probability that an observation is less than $\zeta(\tau)$ is $\tau$, where $0<\tau<1$. Given a set of $T$ observations, $y_{t}, t=1, \ldots T$, the sample quantile, $\zeta(\tau)$, can be obtained by sorting the observations in ascending order. They recoded the residuals associated with a quantile as indicators, in which they define as $\tau$-quantile indicator, listed as follows:

$$
I Q\left(y_{t}-\zeta(\tau)\right)=\left\{\begin{array}{ll}
\tau-1, & \text { if } y_{t}<\zeta(\tau) \\
\tau, & \text { if } y_{t}>\zeta(\tau)
\end{array}, t=1, \ldots, T\right.
$$

\footnotetext{
${ }^{1}$ In the Monte Carlo simulation, a Generalised Pareto Distribution (GPD) is assumed when the return is above the threshold, while an empirical distribution is used when the return is below the threshold.
} 
Busetti and Harvey (2011) comment that a stationarity test statistic based on the $\tau$-quantile may be constructed by using the quantics, $I Q\left(y_{t}-\widetilde{\zeta}(\tau)\right), t=1, \ldots, T$, in the test statistic of Nyblom and Mäkeläinen (1983) in place of the residuals from the sample mean. Busetti and Harvey (2011) further assume that $\zeta(\tau)$ is the unique population $\tau$-quantile and $y$ has a continuous positive density in the neighborhood of $\zeta(\tau)$. They also comment on the work of Busetti and Harvey (2007) which shows that, under the null hypothesis that the observations are independently and identically distributed (IID), the asymptotic distribution of the quantic-based stationarity test statistic is the Cramer von Mises $(\mathrm{C} v \mathrm{M})$ distribution as shown below. A joint test to see if a group of $N$ quantiles or combinations of quantiles show evidence of changing over time can be based on a generalization of the equation below.

$$
\eta_{\tau}(Q)=\frac{1}{T^{2} \tau(1-\tau)} \sum_{t=1}^{T}\left(\sum_{i=1}^{t} I Q\left(y_{i}-\tilde{\zeta}(\tau)\right)\right)^{2}
$$

Busetti and Harvey (2011) suggest that the tests in Busetti and Harvey (2007) are designed to detect movements in the quantiles of the distributions of a univariate series. If the marginal distributions of two time series are time invariant, then the following question is naturally whether their copula is changing over time. As with a univariate series, the tests are based on indicators, but in this case, combinations of quantiles from the two series would have to be used. To simplify matters, quantiles are normally assumed to be the same for the two series to be used to evaluate the probability that both observations lie below their respective $\tau$-quantiles. Stationarity test statistics can then be formed from these bi-quantics provided in Busetti and Harvey (2011) as follows:

$$
\eta_{\tau}(B Q ; B B)=\frac{1}{T^{2} C_{T}(\tau, \tau)\left(1-C_{T}(\tau, \tau)\right)} \sum_{t=1}^{T}\left(\sum_{i=1}^{t} B I Q_{i}(\tau)\right)^{2}
$$

\subsubsection{Coexceedances in the Quantile Regression Framework}

Baur and Schulze (2005) follow the approaches of Poon et al. (2004), Bae et al. (2003) and Chan-Lau et al. (2004) when assessing common occurrences of extreme returns. They investigate the extent of contagion by estimating both the upper and lower tails of the return distributions based on threshold returns. Bae et al. (2003) investigate the effects of contagion by computing the coexceedances and apply a multinomial logistic regression framework to identify factors and to what extent they contribute to contagion. Baur and Schulze (2005), however, investigate the extent of contagion 
by computing and applying the coexceedances in the quantile regression framework. The quantile processes allow the evolution of coexceedances to be shown over the distribution of coexceedance. Baur and Schulze (2005) also analyse the extent to which market announcement events and other market variables contribute to the contagion. Their findings provide different insights into the causes of contagion in time of market crisis.

Baur and Schulze (2005) redefine coexceedances to reveal information on the degrees of coexceedances of the underlying asset returns. In the bivariate case, the coexceedance of two return pairs $r_{1}$ and $r_{2}$ at time $t$ is defined as follows:

$$
\text { Coex }_{t}\left(r_{1}, r_{2}\right)= \begin{cases}\min \left(r_{1 t}, r_{2 t}\right) & \text { if } r_{1 t}>0, r_{2 t}>0 \\ \max \left(r_{1 t}, r_{2 t}\right) & \text { if } r_{1 t}<0, r_{2 t}<0 \\ 0 & \text { otherwise }\end{cases}
$$

In this case, the coexceedance measure is interpreted as the value of (extreme) movement that is shared by both markets. Similar to that in Poon et al. (2004) and Chan-Lau et al. (2004), Baur and Schulze (2005) focus only on two markets. From (4), it can be seen that, the smaller value is chosen should two values exhibit positive returns on the same day. On the other hand, a larger value is picked when two returns exhibit negative returns. This way of defining the 'shared' value is conservative: it tends to bias towards the market that is affected less regardless of the direction of the markets. Therefore, if the conditional value based on the above model is $-2 \%$ in the 'down' market, then both returns are at least $-2 \%$ during the day the observation is made. The conditional value captures a common movement observed from the magnitude of the returns of the two underlying assets. Given the observations documented in Le et al. (2012) that market shocks during the credit crisis period are associated with governmental intervention - both in its initial and in its cleaning-up afterwards - this paper includes similar news of governmental intervention as well as news of financial firms' failures during the periods of credit crisis to assess how their impact on market contagion. Our approach of evaluating market contagion is also supported by Cheung et al. (2010) who suggest that shocks originated from the US during the credit crisis of 2008 has a prolonged worldwide fear and could potentially cause fundamental changes in the correlations among both developed and emerging markets. 


\section{Data}

We use weekly continuously compounded index returns on the stock markets of the following countries: US, UK, Argentina, Brazil, Chile, France, Germany, Hong Kong, Indonesia, Japan, South Korea, Malaysia, Mexico, Singapore, Taiwan, Thailand and the Philippines. For each market, the returns from the Morgan Stanley Country Index (MSCI) for each respective market are used as proxies for stock market performance. Our sample starts from 9/3/2005 and ends in 28/12/2011. The reason for using weekly frequency is that it enables opening and closing trading hours to be properly synchronised. The timeframe covers the period in which news events related to the credit crisis or global recession, presented in Table 1, took place. As a proxy for the risk-free rate, we use the yields on the 3-month T-bills. To evaluate whether contagion is reflected in market sentiments variables, we use VIX as a proxy for investors' sentiments. ${ }^{2}$

We present descriptive statistics of the data in Table 2. All the four European markets have negative mean returns, while the mean returns for the other markets range from $0.001 \%$ (Taiwan) to $0.3366 \%$ (Indonesia). Of all the countries in our sample, Brazil has the highest standard deviation (5.48\%). This can be explained by its lowest minimum return of $-44.5 \%$, even though it has the highest median return of $0.96 \%$. All the markets exhibit negative skewness, implying that the return distributions tend to cluster below the value of mean returns. ${ }^{3}$

Table 3 shows the unconditional correlation structure between all the stock market returns for the whole time span. It can be seen that all the values are positive, thereby reflecting regional and economic relationships. Table 4 divides the correlations into the tranquil and crisis periods ${ }^{4}$. These correlations between markets differ before and during the crisis periods. For example, the correlation measure for Singapore and the US increases from 0.37 before the crisis to 0.68 during the crisis. However, some of the correlation measures do not change or only change very little before and during the crisis periods (such as the correlation coefficients for the UK and Korea). Facing this, Embrechts et al. (2000) offer an alternative explanation: they point out that if the assumption of bivariate normality underlying the stock returns is violated, then correlations may not capture

\footnotetext{
${ }^{2}$ VIX is the Chicago Board Options Exchange Volatility Index. It is based on the volatility implied by options contracts on the S\&P 500 index and is an estimate of future volatility.

${ }^{3}$ Table 2 presents the descriptive statistics for data from 9/3/2005 to 28/12/2011, the entire period for the studies. These are similar when narrowing the period from the first of the news report till the last, i.e., from 2007 to 2009.

${ }^{4}$ We use 2005 and 2006 as the tranquil period, while 2007 to 2009 as the crisis period
} 
the non-linear patterns underlying the data.

Considering Embrechts et al. (2000), we carry out the Mardia's multivariate normality test, discussed in Mardia (1970), that accounts for both skewness and kurtosis. ${ }^{5}$ Our results show that the null hypotheses of bivariate normality between the US, the UK and their respective 15 stock market index returns are all rejected, implying that return correlations are nonlinear throughout the period of study. Table 5 shows that joint negative shocks occur less frequently than joint positive shocks for both the US and the UK markets. The country pairs with the least and the most numbers of observations in our datasets are the US and Taiwan with 229 observations and UK and France with 315 observations, respectively. As we can see in Table 6, all of the distributions of coexceedances are asymmetric and negatively skewed, suggesting that the magnitudes of joint negative shocks are larger than those of joint positive shocks. When both markets fall, they fall sharply. The results in both Tables 5 and 6 strongly support the use of quantile regression technique instead of conventional correlation coefficients to quantify the extent of contagion. We explain our approach in the next section.

\section{Modelling Contagion Effect in a Two-Stage Quantile Regression}

We use a two-stage approach to model the contagion effect. The first stage involves estimating the conditional volatility by fitting the return series — both the UK and the US return series — to the BEKK-GARCH specification which we explain below.

\subsection{The BEKK-GARCH Model}

A natural extension of univariate GARCH, multivariate GARCH approaches allow the conditional variance-covariance matrix to be a function of both lagged values of volatility and covariance, thereby taking into consideration the 'spillover' effect between the crisis-originating stock market (i.e., the US and the UK) and the world stock market when the conditional volatility is estimated. In this paper, we adopt the BEKK-GARCH specification. The restrictions imposed on the BEKK-GARCH is important as they make the model mathematically tractable.

Consider the following system of equations:

\footnotetext{
${ }^{5}$ Please refer to Appendix A.I for more details of the test.
} 


$$
\mathbf{H}_{t}=\mathbf{C}^{\prime} \mathbf{C}+\sum_{i=1}^{q} \mathbf{A}_{i}^{\prime} \varepsilon_{t-i} \varepsilon_{t-i}^{\prime} \mathbf{A}_{i}+\sum_{j=1}^{p} \mathbf{B}_{j}^{\prime} \mathbf{H}_{t-j} \mathbf{B}_{j} .
$$

where $\mathbf{r}_{t}=\varepsilon_{t}$ and $\varepsilon_{t}=\mathbf{H}_{t}^{1 / 2} \mathbf{z}_{t}$. The matrices $\mathbf{A}, \mathbf{B}$ and $\mathbf{C}$ are $n \times n$ matrices. We assume that $\mathbf{C}^{\prime} \mathbf{C}$ is either upper or lower triangular. Note that $n$ is the number of markets to be modelled. In our paper, where $n=2$, the BEKK-GARCH$(1,1)$ can be explicitly written as follows:

$$
\begin{gathered}
{\left[\begin{array}{cc}
\sigma_{i, t}^{2} & \sigma_{i m, t} \\
\sigma_{m i, t} & \sigma_{m, t}^{2}
\end{array}\right]=\left[\begin{array}{cc}
c_{11} & 0 \\
c_{21} & c_{22}
\end{array}\right]+\left[\begin{array}{cc}
a_{11} & a_{21} \\
a_{12} & a_{22}
\end{array}\right]\left[\begin{array}{cc}
\varepsilon_{i, t-1}^{2} & \varepsilon_{i, t-1} \varepsilon_{m, t-1} \\
\varepsilon_{m, t-1} \varepsilon_{i, t-1} & \varepsilon_{m, t-1}^{2}
\end{array}\right]\left[\begin{array}{ll}
a_{11} & a_{12} \\
a_{21} & a_{22}
\end{array}\right]+} \\
\\
{\left[\begin{array}{ll}
b_{11} & b_{21} \\
b_{12} & b_{22}
\end{array}\right]\left[\begin{array}{cc}
\sigma_{i, t-1}^{2} & \sigma_{i m, t-1} \\
\sigma_{m i, t-1} & \sigma_{m, t-1}^{2}
\end{array}\right]\left[\begin{array}{ll}
b_{11} & b_{12} \\
b_{21} & b_{22}
\end{array}\right] .}
\end{gathered}
$$

The parameters in (5) can be estimated using maximum likelihood. (Appendix A.II shows the functional form of the log-likelihood function.) Notice that the BEKK-GARCH model specifies the conditional variance and covariance of one variable as a function of lagged values of the other variables. Specifically, the BEKK-GARCH model is simply a restricted version of the VEC-GARCH model, originally proposed by Bollerslev et al. (1988), but with the conditional variance-covariance matrix constructed to be positive definite. The restriction guarantees convergence when the model is estimated using maximum likelihood.

Similar to Baur and Schulze (2005), we use the calculated conditional volatility as a control variable. This is in response to the argument in Forbes and Rigobon (2002), who state that volatility underlying the datasets could often bias correlation as an effective measure for contagion.

\subsection{Quantile Regression}

In the second stage, we use the quantile regression (QR) technique to investigate the relationship between the coexceedance and the explanatory variables at different points on the distribution of coexceedance. Because of a number of similarities between QR and the ordinary least square (OLS), it is useful to compare and contrast both techniques. Using OLS regression, the parameters of interest $\hat{\beta}$ in a simple linear model $-y_{t}=x_{t}^{\prime} \beta+\varepsilon_{t}-$ measure the responsiveness of $y_{t}$ to $x_{t}$ when $y_{t}$ is assumed to take the mean value. In contrast, QR estimates the conditional quantile function of $y_{t}$ based on $x_{t}$, thus allowing the responsiveness of $y_{t}$ to $x_{t}$ at different quantiles on the distribution 
of $y_{t}$ to be measured.

In this paper, we fit the following QR model to the US and the UK data:

$$
q_{\tau}\left(\operatorname{Coex}_{t} \mid \Omega_{t}\right)=\alpha_{\tau}+\beta_{\tau} D_{t}+\gamma_{\tau} V I X_{t}+\delta_{\tau} \hat{\sigma}_{t}
$$

where $q_{\tau}(\bullet)$ is the conditional quantile function evaluated at the $\tau^{\text {th }}$ quantile; $\Omega_{t}$ is the information set available at time $t ; \alpha_{\tau}, \beta_{\tau}, \gamma_{\tau}$ and $\delta_{\tau}$ are the parameters to be estimated at the $\tau^{\text {th }}$ quantile.

The dummy variable $D_{t}$ takes the value of 1 during the periods corresponding to the news events related to the credit crisis (specifically, for the US and the UK separately) and 0 otherwise. The variable $V I X_{t}$ is the measure of investors' sentiments. And the conditional volatility $\hat{\sigma}_{t}$ is calculated as the square root of $\sigma_{i, t}^{2}$ - an element in the matrix $\mathbf{H}_{t}$ - obtained from (5). For each pair of countries, the coexceedance variable is calculated using the criteria in (4). We discard the observations where the coexceedance takes the value of 0 because they distort the quantile regression results.

For a fixed value of $\tau$, the parameters $\alpha_{\tau}, \beta_{\tau}, \gamma_{\tau}$ and $\delta_{\tau}$ can be estimated by the following linear minimisation:

$$
\min _{\alpha_{\tau}, \beta_{\tau}, \gamma_{\tau}, \delta_{\tau}} \sum_{t=1}^{T} \rho_{\tau}\left[\text { Coex }_{t}-q_{\tau}\left(\text { Coex }_{t} \mid \Omega_{t}\right)\right]
$$

where $\rho_{\tau}(z)$ is the check function given by $\rho_{\tau}(z)=z\left(\tau-1_{[z \leq 0]}\right)$ and where $\rho_{\tau}(z)$ imposes different weights on positive and negative residuals.

As pointed out in Kim and Muller (2008), because the conditional volatility is fitted using the BEKK-GARCH model in the first stage, the intercept term in the two-stage quantile regression is biased. We therefore do not attempt to interpret the intercept term $\hat{\alpha}_{t}$ in this paper. Moreover, we bootstrap the standard errors in the second stage using the technique described in Efron (1987) to obtain correct the standard errors. The number of bootstrap replication for each estimation is 5,000 .

It is worth noting that the parameter $\beta_{\tau}$ reveals information about the behavior of the coexceedance during the crisis period. If, for example, the coefficient $\beta_{\tau}$ is significantly below zero at the lower quantiles (e.g., the $5^{\text {th }}$ quantile), not only we can argue that the (extreme) negative movement shared by both of the markets is significantly lower during the turmoil period, but we are also able to make statements about the severity of the observed contagion. Since the quantile regression model accounts for different regimes of coexceedances, our approach is more informative than existing 
definitions and measures of contagion.

The simple quantile regression specification accounts for any other covariates that potentially have an impact on the structure of the coexceedances. An increased volatility during the crisis period might lead to larger extreme coexceedances, we include a similar parameter in our model. This parameter accounts for the heteroscedasticity underlying the spillover effects between the UK or the US market and the world market. We use VIX as a proxy for the investor's attitude towards global risk as existing literature on contagion shows that investors' sentiment plays an increasing role in the cascading effects of financial crises. Similar application can also be seen in Ismailescu and Kazemi (2011), McGuire and Schrijvers (2003) and Remolona et al. (2007). In this case, an increase (decline) in the volatility index (i.e., the VIX index) is assumed to signal a rise in investors' aversion towards global risk. We expect a positive relationship between VIX and the negative coexceedances and a negative relationship with positive coexceedances. Furthermore, we include the estimated conditional volatility $\hat{\sigma}_{t}$ computed using the BEKK-GARCH model to further assess the spillover effect between the crisis-originating markets and the global stock market on the coexceedances during the credit crisis period. We present our results in the next section.

\section{$5 \quad$ Results and Discussions}

In this section, we present the quantile regression results of Eq. (7). As explained above, the BEKKGARCH model is first fitted to the data on returns for both stock markets; the model specifications for the US and the UK are BEKK-GARCH $(1,1)$ and $\operatorname{BEKK-GARCH}(1,2)$ respectively. ${ }^{6}$ To ensure that the models adequately fit the data, we calculate the Ljung-Box statistics (Ljung and Box, 1978) for both the standardised and the squared standardised residuals for up to 12 lags. The test statistics for the US are 13.64 and 9.08; while the statistics for the UK are 13.95 and 11.71. Under the null hypotheses, the statistics for the US and the UK have chi-square distributions with 10 and 9 degrees of freedom respectively. The results for both the US and the UK suggest that the null hypotheses of the overall insignificance of residual autocorrelations cannot be rejected, implying that the BEKK-GARCH models chosen can adequately explain the data.

Tables 7, 8 and 9 show the quantile regression results for (7) for each of the explanatory variables:

\footnotetext{
${ }^{6}$ We use the Akaike information criteria to select the best-fitting models.
} 
the crisis dummy, market sentiment index (VIX) and the conditional volatility respectively. These three variables are all included in the two stage quantile regression analyses, but findings are separately presented in these three tables to show how they evolve over different quantiles of the distributions.

\subsection{The Effects of the Credit Crisis on the Coexceedances}

Table 7 presents the findings about the effects of the crisis dummy on the coexceedances during the credit crisis periods. The table presents findings of the contagion effect originating from the UK and the US ${ }^{7}$. It can be shown that the dummy remains statistically significant for some of the lower quantiles, indicating evidence of contagion when the stock markets are down. This observation is similar to Baur and Schulze (2005), who observe some evidence of contagion during the Asia Financial Crisis of 1997, pointing to Hong Kong and Thailand as the crisis-originating countries. Our findings show differences in the UK and the US on the contagion effects during the crisis. We observe that the UK market at least has a contagion effect on one of the lower quantiles (i.e., $2^{\text {nd }}$, $4^{t h}, 6^{t h}, 8^{t h}$ and $10^{t h}$ quantiles) of the distributions throughout the period for most of the countries, except for the Mexico and the US markets. In the case of the US market, it appears to have weaker contagion effects. There is no evidence of contagion effect at all for UK, Japan, Argentina, Brazil, Chile, Korea, Singapore and Thailand.

\subsection{The Market Sentiments during the Credit Crisis Periods}

In this section, we investigate the impact of the VIX index on the coexceedance. An increase (decline) in the volatility index is assumed to signal a rise in investors' aversion towards (tolerance of) global risk. A positive relationship between VIX and the negative coexceedances and a negative relationship with the positive coexceedances are therefore expected. Our findings show that, the coexceedances involving the US market depend on market sentiments at the upper quantiles, as it reveals a negative relationship with the VIX indices. In the case of the UK market, it appears that market sentiments do not appear to have much impact on both upper and lower quantiles. This is possible following the effect of the UK governmental intervention efforts as proxied by the crisis dummies as discussed in Section 5.1. This makes it clear that the UK market is driven by the

\footnotetext{
${ }^{7}$ Table 1 lists out the news events and the sources of countries it originated.
} 
specific risk perceptions originating from the news events which are often unscheduled rather than a general market sentiment.

\subsection{The Impact of Conditional Volatility during the Credit Crisis Periods}

Following Baur and Schulze (2005), we include conditional volatility as a control variable in our model. This variable captures the global spillover effect of the UK or the US with their respective paired stock markets. Our findings reveal that the global spillover of the UK or the US has an effect on their respective coexceedances with other countries. However, we find that higher risk in either the UK or the US market has a positive impact on the coexceedance only when the coexceedance is located at the upper quantiles, i.e., when the joint returns on the UK or the US markets with their respective countries pairs are high (i.e., positive). This suggests that, during good times the markets react strongly to good news. Shocks to the aggregate stock markets during the 'up' cycles transmit rapidly across markets resulting in comovements between the two markets.

The effect is observed to be stronger for the coexceedances involving the UK stock market. According to our discussions in Sections 5.1 and 5.2, the UK appears to be affected by news events of the interventions by the UK government as well as firms' failures, which are often unscheduled and unexpected, and with specific underlying risks that may not be factored into the existing market sentiment. This results in higher sensitivity of the UK market to good news, which explains the stronger relationships of the spillover effect between the UK and the rest of the world when the coexceedances of the UK with other countries are higher.

To conclude our discussions, we report the $R^{2}$ values, calculated according to Koenker and Machado (1999) in Table 10. It can be seen that our model fits the data better at the extreme quantiles. The values of $R^{2}$ are somewhat higher when the parameters are evaluated at the tails of the coexceedance distributions. Specifically, the $R^{2}$ values at the $2^{\text {nd }}$ and $98^{\text {th }}$ quantiles are larger than the values reported at the other quantiles.

We also perform tests of equality of parameters, proposed by Koenker and Bassett (1982), to test the null hypotheses that the difference between the values of the parameters at the $10^{\text {th }}$ quantile and the $90^{\text {th }}$ quantile is not statistically significant. We report our results in Table 11 . The results for the UK suggest the following: except for Germany, Mexico, Thailand and the US, the difference between the parameters of the dummy variables at the $10^{\text {th }}$ and $90^{\text {th }}$ quantile is statistically significant at 
the conventional significance levels. As for the coefficients on the conditional volatility, we reject the null hypothesis at the $5 \%$ significance level for all of the countries in our sample. This is also true for the US, except that we cannot reject the null hypotheses for the UK, Indonesia and Taiwan. The results for the US also show the coefficients on the dummy variable and the VIX do not seem to differ at the extreme quantiles.

As indicated earlier in the paper, we employ the conditional volatility as a control variable following recommendations by Forbes and Rigobon (2002) that underlying volatility of dataset to have effects on correlation. Some significant impacts of this variable on the US coexceedances have been earlier discussed. The significantly different effects of conditional volatility at the extreme quantiles, further confirms this for the US market when regarding the coexceedance as an alternative to correlations. However, this is slightly different in the case of the UK. For the UK, the conditional volatility variables are significant at the upper quantile and significantly different effects were observed at extreme quantiles. Even so, the dummy variables are significant for most countries, indicating that news events have a notable impact on the co-movements of stock returns at the extreme quantiles.

\section{Conclusions}

The Global Financial Crisis began in 2007 when the subprime mortgage crisis, originated in the US, spread rapidly to most financial markets around the globe, causing large volatility in the stock markets. The crisis has motivated research such as that of Cheung et al. (2010) to study how shocks originated from the dominant US market promptly and pervasively spilled over into other markets, resulting in intensified interdependence among the global stock markets. Such research is important as — unlike all previous crises such as the 1997 Asian financial crisis, the 1998 Russian financial crisis, and the 1999 Brazilian crisis — the latest crisis originated from the largest and most influential economy, the US.

Research similar to Cheung et al. (2010) often focuses on anlaysing the impact of crisis on the volatility and patterns of the stock markets during the period of the credit crisis. This includes Dontis-Charitos et al. (2013) who investigate the return and volatility spillovers among the US and other international markets during the period between 2007 to 2009. Their findings reveal the presence of intensified return and volatility spillovers from the US to a number of markets. During 
this period, various news events took place whose effects on the stock markets cannot be ignored. It has been shown by Tetlock (2007) that negative reports by the media underlying the news events during the crisis do predict downward pressure on market prices. In this paper, we use the quantile regression model along with the coexceedance as a contagion measure to assess the extent to which such news events contribute to contagion in the stock markets during the crisis period. A study by Rachdi (2013) has shown that, not only the subprime crisis leads to a global recession, but the effects on the global stock markets have been significant. Our findings provide additional insights into these effects.

Our research also reveals some interesting findings. We find that in the case of the US, no significant contagion effects were observed. Though most of the news events from the US were of similar nature to that of the UK, such as bank failure or the bailing out of failing banks. There were news, however, that were welcomed by the markets, such as those relating to the Fed's monetary easing, providing a lifeline to the financial markets. Such news event is considered to be "promising policy steps to resolve the crisis" as suggested in Aït-Sahalia et al. (2012), which the empirical evidence from our research lends support to. Their paper examines the impact of macroeconomics and financial sector policy announcements in the US, UK, the euro area, and Japan on interbank credit and liquidity risk premia. Their findings reveal that, overall, news events related to the policy interventions are associated with a reduction in the interbank risk premia, most significantly for recapitalization programs. By contrast, news events about the bail out of individual banks in an ad hoc manner or let them fail are accompanied by a significant rise in the interbank risk premia.

In the case of the UK, our analysis shows that news events are associated with the contagion effect in the stock markets. The rescue of Lloyds TSB by the UK government after the bank merged with HBOS is an example. As Aït-Sahalia et al. (2012) comment, “.. Ad hoc bailouts targeted at individual systemic institutions were accompanied by a worsening of market fears, possibly because they were perceived as a signal that problems in the financial sector were worse than originally assumed by markets ..." Their findings are consistent with our results for the UK, as the rescue required an additional $£ 175$ billions — the amount reported to be a record high. ${ }^{8}$

Our approach deviates from several existing literatures such as Klomp (2013) and Greatrex

${ }^{8}$ Information provided by the global timeline as found on the BBC website
(http://news.bbc.co.uk/1/hi/business/8242825.stm).


and Rengifo (2010). Klomp (2013) uses data on credit default swaps (CDS) as a benchmark to estimate the impact of similar news events during the period of the credit crisis while Greatrex and Rengifo (2010) examines the effects of government intervention during the 2007-2009 Financial Crisis on CDS prices using a cross-section of 348 firms from both the financial and non-financial sectors. They further find that the reaction to government actions is stronger for financial firms than for non-financial firms.

Even though we use data on stock market indices (MSCI) in our paper, further investigations into the contagion effects specifically on the finance and banking sector of each country will no doubt likely to reveal more precise impacts on these sectors. Nevertheless, we observe some significant contagion of the news events, particularly those from the UK. This can be explained by the relationship of the information content of news story and its underlying implications, which reinforces the argument that spreads and contagion - an outcome of the risk perception of financial markets — are solely a result of the behaviour of investors or other financial market participants as suggested by Dornbusch et al. (2001).

\section{References}

Aït-Sahalia, Y., Adritzky, J., Jobst, A., Nowak, S., Tamirisa, N., 2012. Market response to policy initiatives during the global financial crisis. Journal of International Economics 87 (1), 162-177.

Bae, K.-H., Karolyi, G. A., Stulz, R. M., 2003. A new approach to measuring financial contagion. Review of Financial Studies 16 (3), 717-763.

Baur, D., Schulze, N., 2005. Coexceedances in financial markets - a quantile regression analysis of contagion. Emerging Markets Review 6, 21-43.

Bollerslev, T., Engle, R. F., Wooldridge, J. M., 1988. A capital asset pricing model with time-varying covariances. Journal of Political Economy 96, 116-131.

Busetti, F., Harvey, A., 2007. Tests of time-invariance based on quantile indicators. CWPE 0657, Faculty of Economics, Cambridge University.

Busetti, F., Harvey, A., 2011. When is a copula constant? A test for changing relationships. Journal of Financial Econometrics 9 (1), 106-131. 
Chan-Lau, J. A., Mathieson, D. J., Yao, J. Y., 2004. Extreme contagion in equity markets. IMF Staff Papers $51(2), 8$.

Cheung, W., Fung, S., Tsai, S.-C., 2010. Global capital market interdependence and spillover effect of credit risk: evidence from the 2007-2009 global financial crisis. Applied Financial Economics 20, $85-103$.

Dontis-Charitos, P., Jory, S. R., Ngo, T. N., Nowman, K. B., 2013. A multi-country analysis of the 2007-2009 financial crisis: Empirical results from discrete and continuous time models. Applied Financial Economics 23 (11), 929-950.

Dornbusch, R., Park, Y. C., Claessens, S., 2001. Contagion: how it spreads and how it can be stopped? In: Claessens, S., Forbes, K. (Eds.), International Financial Contagion. Kluwer Academic, New York, p. 761.

Dungey, M., Fry, R., Gonzàlez-Hermosillo, B., Martin, V., 2005. Empirical modelling of contagion: A review of methodologies. Quantitative Finance (5), 9-24.

Efron, B., 1987. The Jackknife, the Bootstrap and Other Resampling Plans. Society for Industrial Mathematics.

Eichengreen, B., Rose, A., Wyplosz, C., 1995. Exchange market mayhem: The antecedents and aftermath of speculative attacks. Economic Policy 21, 249-312.

Eichengreen, B., Rose, A., Wyplosz, C., 1996. Contagious currency crises. NBER Working Paper 5681, National Bureau of Economic Research.

Embrechts, P., McNeil, A., Straumann, D., 2000. Correlation and dependence in risk management: Properties and pitfalls. In: Dempster, M., Moffatt, H. K. (Eds.), Risk management: value at risk and beyond. Cambridge University Press.

Forbes, K. J., Rigobon, R., 2002. No contagion, only interdependence: measuring stock market comovements. Journal of Finance 57 (5), 2223-2261.

Greatrex, C. A., Rengifo, E. W., 2010. Government intervention and the CDS market: A look at 
the market's response to policy announcements during the 2007-2009 Financial Crisis. Discussion Paper Series 12, Department of Economics, Fordham University.

Hosmer, D. W., Lemeshow, S., 1989. Applied Logistic Regression. Wiley.

Ismailescu, I., Kazemi, H., 2011. Contagion or interdependence in emerging debt markets? Banking and Finance Review 3 (2), 1-16.

Joliffe, I. T., 1986. Principal Component Analysis. New York: Springer-Verlag.

Kim, T.-H., Muller, C., 2008. Bias tranmission and variance reduction in two-stage estimation. Discussion paper, Yonsei University.

Klomp, J., 2013. Government interventions and default risk: Does one size fit all? Journal of Financial Stability 9, 641-653.

Koenker, R., Bassett, G., 1978. Regression quantiles. Econometrica 46 (1), 33-50.

Koenker, R., Bassett, G., 1982. Robust tests for heteroskedasticity based on regression quantiles. Econometrica 50 (1), 43-62.

Koenker, R., D’Orey, V., 1987. Computing regression quantiles. Applied Statistics 36, 383-393.

Koenker, R., D’Orey, V., 1997. Computing regression quantiles. Applied Statistics 43, 410-414.

Koenker, R., Machado, J. A. F., 1999. Goodness of fit and related inference processes for quantile regression. Journal of American Statistical Association 94 (448), 1296-1310.

Le, V. P. M., Meenagh, D., Minford, P., 2012. What causes banking crises? An empirical investigation. CEPR Discussion Papers 9057, Centre for Economic Policy Research.

Ljung, G., Box, G., 1978. On a measure of lack of fit in time series models. Biometrika 65, 297-303.

Mahalanobis, P. C., 1936. On the generalised distance in statistic. In: Proceedings of the National Institute of Sciences of India.

Mardia, K., 1970. Measures of multivariate skewness and kurtosis with applications. Biometrika 57, 519-530. 
McGuire, P., Schrijvers, M. A., 2003. Common factors in emerging market spreads. BIS Quarterly Review, 65-78.

Mishkin, F. S., 2011. Over the cliff: From the subprime to the global financial crisis. Journal of Economic Perspectives 25 (1), 49-70.

Nyblom, J., Mäkeläinen, T., 1983. Comparisons of tests for the presence of random walk coefficients in a simple linear model. Journal of American Statistical Association 78 (384), 856-864.

Poon, S.-H., Rockinger, M., Tawn, J., 2004. Extreme value dependence in financial markets: diagnostics, models, and financial implications. The Review of Financial Studies 17 (2), 581-610.

Rachdi, H., 2013. The impact of the international financial crisis on the stock market return: The case of Tunisian stock exchange. Journal of Empirical Economics 1 (2), 67-74.

Remolona, E. M., Scatigna, M., Wu, E., 2007. Interpreting sovereign spreads. BIS Quarterly Review, $27-39$.

Sweeting, P., 2010. Financial Enterprise Risk Management. Cambridge University Press.

Tetlock, P. C., 2007. Giving content to investor sentiment: The role of media in the stock market. Journal of Finance 62 (3), 1139-1168. 


\section{Appendices}

\section{A.I}

This appendix discusses the derivation of the Mardia's tests for multivariate normality. It is briefly redeveloped from Sweeting (2010). Numerical tests based on measures of multivariate (bivariate) skew and kurtosis, known as Mardia's test can be derived to test multivariate normality of data sets or data pairs. To test whether observations are from a multivariate normal distribution, tests are normally carried out jointly. Useful statistics in this regard are the the Mahalanobis distance and the Mahalanobis angle Mahalanobis (1936). Mahalanobis distance deals with outliers within datasets by identifying observations that lie far away from the centre of the data cloud, giving less weight to variables with large variances or to groups of highly correlated variables Joliffe (1986). We discuss the computation of the Mahalanobis distance as follows:

Consider the column vector $X_{t}$ which contains the observations at time $t$ where $t=1,2, \ldots, T$ for a group of $N$ variables, so $X_{t}^{\prime}=\left(X_{1, t}, X_{2, t}, \ldots, X_{N, t}\right)$. Let the column vector $\bar{X}$ contain the sample mean for each variable calculated over all $t=1,2, \ldots, T$ so $\bar{X}_{t}^{\prime}=\left(\bar{X}_{1}, \bar{X}_{2}, \ldots, \bar{X}_{N}\right)$. Then, let $S$ be an $N \times N$ matrix of the sample covariances of the $N$ variables based on the observations from $t=1,2, \ldots, T:$

$$
\left[\begin{array}{cccc}
S_{X_{1} X_{1}} & S_{X_{1} X_{2}} & \cdots & S_{X_{1} X_{N}} \\
S_{X_{2} X_{1}} & S_{X_{2} X_{2}} & \cdots & S_{X_{2} X_{N}} \\
\vdots & \vdots & \ddots & \vdots \\
S_{X_{N} X_{1}} & S_{X_{N} X_{2}} & \cdots & S_{X_{N} X_{N}}
\end{array}\right]
$$

where $S_{X_{n}, X_{m}}$ is the sample covariance between the observations for variables $m$ and $n$ calculated over all $i=1,2, \ldots, T$, and where $S_{X_{n}, X_{n}}=S_{X_{n}}^{2}$, the variance of the observations for variable $n$. The Mahalanobis distance at time $t, D_{t}$ is then calculated as:

$$
D_{t}=\sqrt{\left(X_{t}-\bar{X}\right)^{\prime} S^{-1}\left(X_{t}-\bar{X}\right)}
$$

Squaring the Mahalanobis distance gives the statistic that is the sum of $N$ normal variables, if the variables are drawn from a multivariate normal distribution. The statistic $D_{t}^{2}$ therefore has a $\chi^{2}$ distribution with $N$ degrees of freedom. It is possible to derive numerical tests based on measures 
of multivariate skew and kurtosis, known as Mardia's tests Mardia (1970), and this involves firstly to define the Mahalanobis angle between observations at times $s$ and $t, D_{s, t}$ :

$$
D_{s, t}=\left(X_{s}-\bar{X}\right)^{\prime} S^{-1}\left(X_{t}-\bar{X}\right)
$$

Following that, a skew-type parameter, $W_{N}$ can be calculated:

$$
W_{N}=\frac{1}{T^{2}} \sum_{s=1}^{T} \sum_{t=1}^{T} D_{s, t}^{3}
$$

Multiplying this by $T / 6$ gives Mardia's skew test statistic, $M S T$, that has a $\chi^{2}$ distribution with $N(N+1)(N+2) / 6$ degrees of freedom, which will be the case under the null hypothesis where it will be a standard normal

$$
M S T=\frac{T}{6} W_{N} \sim X_{N(N+1)(N+2) / 6}^{2}
$$

For Mardia's test of multivariate kurtosis, the kurtosis-type parameter, $K_{N}$, is, however, calculated from the Mahalanobis distance:

$$
K_{N}=\frac{1}{T} \sum_{i=1}^{T} D_{t}^{4}
$$

This can be transformed into Mardia's Kurtosis test statistic, $M K T$, which tends to a standard normal distribution as $T$ tends to infinity:

$$
M K T=\frac{K_{N} \sim N(N+2)}{\sqrt{8 N(N+2) / T}} \backsim N(0,1)
$$

The three sets of 15 stock returns' pairs, of which each involved the UK, US and the world indexes are tested for multivariate normality based on Mardia's multivariate skewness and multivariate kurtosis, MST and MKT as above derived and defined. Our results show the null hypothesis of multivariate normality are rejected for all three sets of the 15 stock returns' pairs at 1\%, $5 \%$ and $10 \%$ significant levels. This implies the potential size dependent biases exist underlying the correlations of the stock returns' pairs involving the UK and the US stock markets, which directly supports the use of the Quantile Regression approach along side coexceedance measures (from Baur and Schulze, 
2005). Quantile Regression measures relationship between variables on different quantiles of the distribution, which automatically accounts for the size effects. This is therefore a relatively more appropriate measure of contagion compared to that of correlation. All multivariate normality tests used in this paper are all performed in Matlab.

\section{A.II}

In the BEKK-GARCH model the parameters of the conditional variance and conditional covariance equations are estimated simultaneously by maximising the following log-likelihood function:

$$
\ln L(\theta)=-\frac{1}{2} \sum_{t=1}^{T}\left(\ln \left(\left|\mathbf{H}_{t}\right|\right)+\varepsilon_{t}^{\prime} \mathbf{H}_{t}^{-1} \varepsilon_{t}\right)
$$

where $\mathbf{H}_{t}$ is the conditional covariance matrix and $\varepsilon_{t}$ is the GARCH error vector at time $t$.

\section{A.III}

The quantile regression was first introduced by Koenker and Bassett (1978). The model assumes that

$$
\operatorname{Pr}\left(y_{i} \leq \tau \mid x_{i}\right)=F_{u_{\theta}}\left(\tau-x_{i}^{\prime} \beta_{\tau} \mid x_{i}\right)
$$

where $i=1, \ldots, n,\left(y_{i}, x_{i}\right)$ is a sample from some population and $x_{i}$ is a $K \times 1$ vector of regressors. Readers may be more familiar with representation with the following functional form:

$$
y_{i}=x_{i}^{\prime} \beta_{\tau}+u_{\tau_{i}}
$$

and

$$
q_{\tau}\left(y_{i} \mid x_{i}\right)=x_{i}^{\prime} \beta_{\tau}
$$

where $q_{\tau}\left(y_{i} \mid x_{i}\right)$ is the conditional quantile of $y_{i}$ conditional on the regressor vector $x_{i}$.

The model assumes further that $q_{\tau}\left(u_{\tau_{i}} \mid x_{i}\right)=0$. The estimator of $\beta_{\tau}$ at the $\tau^{\text {th }}$ quantile, $\hat{\beta}_{\tau}$, is the solution to the following minimisation problem:

$$
\min _{\beta} \sum_{i=1}^{n} \rho_{\tau}\left(u_{\tau_{i}}\right)=\min _{\beta}\left\{\sum_{i: y_{i} \geq x_{i}^{\prime} \beta} \tau\left|y_{i}-x_{i}^{\prime} \beta\right|+\sum_{i: y_{i} \leq x_{i}^{\prime} \beta}(1-\tau)\left|y_{i}-x_{i}^{\prime} \beta\right|\right\}
$$


where $\rho_{\tau}(z)$ is the check function given by $\rho_{\tau}(z)=z\left(\tau-1_{[z \leq 0]}\right)$.

In this paper, we use the modified version of the Barrodale and Roberts algorithm to solve the linear minimisation problem in (20). Both Koenker and D'Orey (1987) and Koenker and D'Orey (1997) recommend the algorithm for problems up to several thousand observations. All the estimations in this paper are performed in $\mathrm{R}$. 
Table 1: Lists of News Events between 2007 and 2009 related to the credit crisis

\begin{tabular}{|c|c|c|c|}
\hline No.* & $\begin{array}{l}\text { Event } \\
\text { dates }\end{array}$ & Event headlines & Brief descriptions** \\
\hline 1 & $8 / 2 / 2007$ & $\begin{array}{l}\text { HSBC WARNS } \\
\text { OF SUBPRIME } \\
\text { LOSSES }\end{array}$ & $\begin{array}{l}\text { HSBC reveals huge losses at its US mortgage arm } \\
\text { Household Finance due to subprime losses, in one } \\
\text { of the first signs that the US housing market is } \\
\text { turning sour, and that it could have a knock-on } \\
\text { effect on the global financial sector. }\end{array}$ \\
\hline 2 & $2 / 4 / 2007$ & $\begin{array}{l}\text { NEW } \\
\text { CENTURY } \\
\text { GOES BUST }\end{array}$ & $\begin{array}{l}\text { New Century Financial, a leading subprime lender, } \\
\text { files for } \\
\text { bankruptcy. It is the first signal that something is } \\
\text { seriously amiss at US mortgage lenders. }\end{array}$ \\
\hline 3 & $9 / 8 / 2007$ & $\begin{array}{l}\text { CREDIT } \\
\text { MARKETS } \\
\text { FREEZE }\end{array}$ & $\begin{array}{l}\text { Credit markets go into freefall after Paribas } \\
\text { announces that two of its hedge funds are frozen } \\
\text { due to "complete evaporation of liquidity" in asset } \\
\text { backed security market. }\end{array}$ \\
\hline 4 & $14 / 9 / 2007$ & $\begin{array}{l}\text { RUN ON THE } \\
\text { ROCK }\end{array}$ & $\begin{array}{l}\text { Savers in beleaguered UK former building society } \\
\text { Northern Rock begin withdrawing their savings } \\
\text { after the BBC reveals the bank has received } \\
\text { emergency financial support from the Bank of } \\
\text { England. }\end{array}$ \\
\hline 5 & $17 / 3 / 2008$ & $\begin{array}{l}\text { BEAR } \\
\text { STEARNS } \\
\text { RESCUE }\end{array}$ & $\begin{array}{l}\text { US investment bank Bear Stearns is rescued by } \\
\text { rival bank JP Morgan Chase after the US } \\
\text { government provides a } \$ 30 \text { bn guarantee against its } \\
\text { mounting losses. It is the first sign that, rather than } \\
\text { easing, the financial crisis is getting worse but } \\
\text { investors are relieved that US government prepared } \\
\text { to act as lender of last resort. }\end{array}$ \\
\hline 6 & $7 / 9 / 2008$ & $\begin{array}{l}\text { FANNIE MAE } \\
\text { RESCUE }\end{array}$ & $\begin{array}{l}\text { US government rescues giant mortgage lenders } \\
\text { Fannie Mae and Freddie Mac, taking them into } \\
\text { temporary public ownership after they reveal huge } \\
\text { losses on the US subprime mortgage market. }\end{array}$ \\
\hline 7 & $15 / 9 / 2008$ & $\begin{array}{l}\text { LEHMAN } \\
\text { BROTHERS } \\
\text { GOES } \\
\text { BANKRUPT }\end{array}$ & $\begin{array}{l}\text { US investment bank Lehman Brothers goes } \\
\text { bankrupt after the US government refuses to bail it } \\
\text { out. Merrill Lynch is bought by Bank of America } \\
\text { after revealing it also is facing huge losses. } \\
\text { Insurance firm AIG, which issued credit guarantees } \\
\text { for subprime mortgages, is rescued } \\
\text { the next day with an } \$ 85 \text { bn loan from US Treasury. }\end{array}$ \\
\hline 8 & $17 / 9 / 2008$ & $\begin{array}{l}\text { LLOYDS } \\
\text { TAKES OVER } \\
\text { HBOS }\end{array}$ & $\begin{array}{l}\text { Lloyds agrees a } £ 12.2 \text { bn takeover of the ailing } \\
\text { Halifax Bank of Scotland (HBOS), the UK's largest } \\
\text { mortgage lender, after its shares plummet amid } \\
\text { concerns over the firm's future. The UK }\end{array}$ \\
\hline
\end{tabular}




\begin{tabular}{|c|c|c|c|}
\hline & & & $\begin{array}{l}\text { government invokes a national interest clause to } \\
\text { bypass competition law, as the new bank is } \\
\text { responsible for close to one-third of the UK's } \\
\text { savings and } \\
\text { mortgage market. }\end{array}$ \\
\hline 9 & $3 / 10 / 2008$ & $\begin{array}{l}\text { \$700BN } \\
\text { BAILOUT } \\
\text { APPROVED BY } \\
\text { CONGRESS }\end{array}$ & $\begin{array}{l}\text { The biggest financial rescue in US history is } \\
\text { approved after a gruelling debate in Congress, and } \\
\text { initial defeat a week earlier. Republicans and } \\
\text { Democrats alike were reluctant to bail out the banks } \\
\text { with such large sums while ordinary citizens were } \\
\text { suffering in the recession. Both presidential } \\
\text { candidates endorse the bail-out. }\end{array}$ \\
\hline 10 & $13 / 10 / 2008$ & $\begin{array}{l}\text { UK } \\
\text { GOVERNMENT } \\
\text { RESCUES RBS } \\
\text { AND LLOYDS- } \\
\text { HBOS }\end{array}$ & $\begin{array}{l}\text { Two of the UK's major banks, RBS and HBOS, are } \\
\text { in major trouble as financial markets collapse. } \\
\text { Having merged with HBOS in September, Lloyds is } \\
\text { hit by the huge debts built up by its new partner in } \\
\text { the mortgage market, while RBS is struggling with } \\
\text { its expensive merger with ABN-AMRO. The UK } \\
\text { government injects } £ 37 \mathrm{bn} \text { to stabilise both banks. }\end{array}$ \\
\hline 11 & $16 / 12 / 2008$ & $\begin{array}{l}\text { FED CUTS } \\
\text { KEY RATE TO } \\
\text { NEAR ZERO }\end{array}$ & $\begin{array}{l}\text { The US central bank cuts its interest rate to } 0 \text { - } \\
0.25 \% \text { in an attempt to stem the deepening } \\
\text { recession, and begins to consider a programme of } \\
\text { quantitative easing to throw money into the } \\
\text { economy to help make } \\
\text { borrowing easier. It is the lowest interest in the } \\
\text { history of the Fed. }\end{array}$ \\
\hline 12 & $14 / 2 / 2009$ & $\begin{array}{l}\text { US CONGRESS } \\
\text { PASSES } \\
\text { \$787BN } \\
\text { STIMULUS }\end{array}$ & $\begin{array}{l}\text { President Obama wins his first major victory in } \\
\text { Congress as it passes a huge economic recovery } \\
\text { plan aimed at preventing the US falling into } \\
\text { recession as a result of the credit crunch. }\end{array}$ \\
\hline 13 & $22 / 4 / 2009$ & $\begin{array}{l}\text { UK BUDGET } \\
\text { REVEALS } \\
\text { HUGE DEFICIT }\end{array}$ & $\begin{array}{l}\text { The UK Chancellor Alistair Darling reveals that the } \\
\text { credit crunch will lead to the largest budget deficit } \\
\text { in UK financial history of } £ 175 \text { bn, with total } \\
\text { government debt set to double to } £ 1 \text { trillion by } \\
2014 \text {. }\end{array}$ \\
\hline
\end{tabular}

* We use event nos. 1, 2, 5, 6, 7, 9, 11 and 12 as news originated from the US, and the remaining events originated from the UK.

** More details about the News Stories are accessible from the chart on Global Recession Timeline by following the link, http://news.bbc.co.uk/1/hi/business/8242825.stm 
Table 2: Descriptive statistics

\begin{tabular}{l|ccccccc}
\hline & Mean & Median & Max & Min & Std. Dev. & Skewness & Kurtosis \\
\hline \hline US & 0.0144 & 0.2425 & 9.6558 & -16.7475 & 2.6790 & -1.1465 & 9.2982 \\
UK & -0.0393 & 0.2529 & 9.7916 & -15.2200 & 3.3980 & -0.7141 & 5.4434 \\
Germany & -0.0008 & 0.4373 & 12.8981 & -17.5035 & 3.9888 & -0.9613 & 6.2711 \\
France & -0.0732 & 0.2283 & 11.7826 & -17.5809 & 3.8518 & -0.6957 & 5.4163 \\
Japan & -0.0573 & 0.1502 & 13.6066 & -15.0566 & 2.8889 & -0.4355 & 6.2798 \\
Argentina & 0.1058 & 0.4734 & 27.2433 & -23.0665 & 4.9655 & -0.2445 & 7.1814 \\
Brazil & 0.2486 & 0.9572 & 13.1659 & -44.5338 & 5.4799 & -1.9059 & 15.0795 \\
Chile & 0.2240 & 0.4879 & 13.9037 & -32.5032 & 3.7422 & -1.9180 & 19.3116 \\
Mexico & 0.1795 & 0.4984 & 13.8131 & -37.3137 & 4.3913 & -2.0195 & 17.7523 \\
Hong Kong & 0.0792 & 0.1337 & 14.0331 & -15.7986 & 3.3433 & -0.1570 & 6.2682 \\
Indonesia & 0.3366 & 0.8284 & 23.2931 & -31.8198 & 5.1684 & -0.8710 & 9.8148 \\
Korea & 0.1273 & 0.6139 & 30.0234 & -26.4848 & 5.1003 & -0.4464 & 10.2982 \\
Malaysia & 0.1910 & 0.3892 & 13.1125 & -10.1609 & 2.6639 & -0.2014 & 5.0473 \\
The Phillipines & 0.1881 & 0.1081 & 14.2098 & -16.3804 & 3.9250 & -0.2588 & 4.5827 \\
Singapore & 0.1074 & 0.4527 & 18.3912 & -17.0474 & 3.5505 & -0.2347 & 7.3540 \\
Taiwan & 0.0010 & 0.3833 & 18.0963 & -12.5569 & 3.7343 & -0.0920 & 5.3344 \\
Thailand & 0.1559 & 0.5803 & 21.9321 & -22.8786 & 4.4204 & -0.4367 & 7.0393 \\
\hline
\end{tabular}


Table 3: Unconditional pairwise correlations between all analysed markets

\begin{tabular}{|c|c|c|c|c|c|c|c|c|c|c|c|c|c|c|c|c|c|}
\hline & US & UK & Ger & Fra & Jap & Arg & $\mathrm{Bra}$ & Chi & Mex & $\mathrm{HK}$ & Ind & Kor & Mal & Phi & Sin & Tai & Tha \\
\hline US & 1.00 & & & & & & & & & & & & & & & & \\
\hline UK & 0.58 & 1.00 & & & & & & & & & & & & & & & \\
\hline Germany & 0.66 & 0.83 & 1.00 & & & & & & & & & & & & & & \\
\hline France & 0.66 & 0.86 & 0.96 & 1.00 & & & & & & & & & & & & & \\
\hline Japan & 0.39 & 0.62 & 0.61 & 0.61 & 1.00 & & & & & & & & & & & & \\
\hline Argentina & 0.59 & 0.58 & 0.57 & 0.60 & 0.41 & 1.00 & & & & & & & & & & & \\
\hline Brazil & 0.59 & 0.73 & 0.69 & 0.70 & 0.56 & 0.63 & 1.00 & & & & & & & & & & \\
\hline Chile & 0.51 & 0.58 & 0.62 & 0.61 & 0.50 & 0.49 & 0.62 & 1.00 & & & & & & & & & \\
\hline Mexico & 0.69 & 0.72 & 0.72 & 0.73 & 0.53 & 0.55 & 0.76 & 0.61 & 1.00 & & & & & & & & \\
\hline Hong Kong & 0.54 & 0.59 & 0.56 & 0.56 & 0.57 & 0.43 & 0.55 & 0.59 & 0.62 & 1.00 & & & & & & & \\
\hline Indonesia & 0.39 & 0.57 & 0.55 & 0.57 & 0.60 & 0.38 & 0.50 & 0.55 & 0.53 & 0.60 & 1.00 & & & & & & \\
\hline Korea & 0.45 & 0.63 & 0.65 & 0.66 & 0.65 & 0.47 & 0.58 & 0.58 & 0.60 & 0.63 & 0.56 & 1.00 & & & & & \\
\hline Malaysia & 0.31 & 0.51 & 0.48 & 0.48 & 0.49 & 0.33 & 0.41 & 0.51 & 0.44 & 0.57 & 0.50 & 0.46 & 1.00 & & & & \\
\hline The Phillipines & 0.43 & 0.49 & 0.47 & 0.50 & 0.58 & 0.31 & 0.52 & 0.45 & 0.50 & 0.55 & 0.55 & 0.50 & 0.50 & 1.00 & & & \\
\hline Singapore & 0.37 & 0.61 & 0.61 & 0.62 & 0.66 & 0.34 & 0.53 & 0.55 & 0.54 & 0.70 & 0.70 & 0.66 & 0.72 & 0.61 & 1.00 & & \\
\hline Taiwan & 0.38 & 0.49 & 0.51 & 0.51 & 0.58 & 0.32 & 0.46 & 0.49 & 0.49 & 0.64 & 0.64 & 0.70 & 0.54 & 0.48 & 0.70 & 1.00 & \\
\hline Thailand & 0.31 & 0.64 & 0.58 & 0.59 & 0.63 & 0.44 & 0.59 & 0.48 & 0.53 & 0.42 & 0.53 & 0.62 & 0.55 & 0.50 & 0.62 & 0.56 & 1.00 \\
\hline
\end{tabular}

Table 4: Comparison of the correlation during the tranquil and crisis period for the US and the UK as origins

\begin{tabular}{|c|c|c|c|c|c|c|c|c|c|c|c|c|c|c|c|c|c|}
\hline & US & UK & Ger & Fra & Jap & Arg & Bra & Chi & Mex & HK & Ind & Kor & $\mathrm{Mal}$ & Phi & Sin & Tai & Tha \\
\hline US & 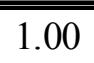 & "0.58 & "0.66 & "0.66 & 0.39 & 0.59 & 0.59 & "0.51 & 0.69 & (0.54 & 0.39 & 0.45 & (20.31 & "0.43 & "0.37 & "0.38 & 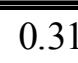 \\
\hline US (Crisis) & 1.00 & 0.81 & 0.76 & 0.80 & 0.59 & 0.57 & 0.79 & 0.62 & 0.81 & 0.64 & 0.47 & 0.47 & 0.45 & 0.44 & 0.68 & 0.52 & 0.50 \\
\hline UK & 0.58 & 1.00 & 0.83 & 0.86 & 0.62 & 0.58 & 0.73 & 0.58 & 0.72 & 0.59 & 0.57 & 0.63 & 0.51 & 0.49 & 0.61 & 0.49 & 0.64 \\
\hline UK (Crisis) & 0.81 & 1.00 & 0.89 & 0.93 & 0.67 & 0.69 & 0.80 & 0.64 & 0.74 & 0.70 & 0.57 & 0.61 & 0.60 & 0.57 & 0.77 & 0.67 & 0.59 \\
\hline
\end{tabular}


Table 5: Percentages of coexceedances

\begin{tabular}{|c|c|c|c|c|c|c|c|c|c|c|c|c|c|c|c|c|c|}
\hline & US & UK & Ger & Fra & Jap & Arg & Bra & Chi & Mex & $\mathrm{HK}$ & Ind & Kor & Mal & Phi & Sin & Tai & Tha \\
\hline US ( & $\mathrm{n} / \mathrm{a}$ & 3 & 31.55 & 32.96 & & & & & & & & & & & & & \\
\hline US & $\mathrm{n} / \mathrm{a}$ & 45.35 & 45.35 & & & & 46.76 & & & & & 40. & & & & 75 & 40.85 \\
\hline UK & 4.37 & $\mathrm{n} / \mathrm{a}$ & 36.34 & 38.87 & 33.24 & 31.55 & 33.52 & 31.83 & 31.5 & 34.08 & 27.04 & 31.83 & 31.83 & 32.39 & 32.96 & 29.86 & 30.42 \\
\hline UK (Positive) & 5.35 & $\mathrm{n} / \mathrm{a}$ & 48.45 & 49.86 & 39.44 & 40.56 & 46.76 & 42.82 & 41.69 & 41.41 & 41.97 & 41.41 & 43.66 & 38.87 & 46.20 & 39.15 & 41.97 \\
\hline
\end{tabular}

Table 6: Skewness of coexceedances

\begin{tabular}{|c|c|c|c|c|c|c|c|c|c|c|c|c|c|c|c|c|c|}
\hline & US & UK & Ger & Fra & Jap & Arg & Bra & Chi & Mex & $\mathrm{HK}$ & Ind & Kor & Mal & Phi & Sin & Tai & Tha \\
\hline US & $\mathrm{n} / \mathrm{a}$ & -1.58 & -1.80 & -1.71 & -2.35 & -2.05 & -1.53 & -1.98 & -1.42 & -1.98 & -2.63 & -2.10 & & -1.55 & -2.03 & -1.62 & -2.25 \\
\hline US (e & $\mathrm{n} / \mathrm{a}$ & -1.40 & -1.59 & -1.51 & -1.86 & -1.72 & -1.38 & -1.73 & -1.27 & -1.66 & -2.15 & -1.76 & -0.80 & -1.29 & -1.70 & -1.2 & -1.86 \\
\hline UK & -1.58 & $\mathrm{n} / \mathrm{a}$ & -1.00 & -0.91 & -1.38 & -1.00 & -0.96 & -0.81 & -1.09 & -0.96 & -1.03 & -1.17 & -0.37 & -0.66 & -1.01 & -1.07 & -0.80 \\
\hline UK (excl. 0) & -1.40 & $\mathrm{n} / \mathrm{a}$ & -0.92 & -0.85 & -1.14 & -0.82 & -0.86 & -0.75 & -0.95 & -0.81 & -0.87 & -0.98 & -0.36 & -0.55 & -0.89 & -0.85 & -0.68 \\
\hline
\end{tabular}


Table 7: Quantile regression estimates for the dummy variable

\begin{tabular}{|c|c|c|c|c|c|c|c|c|c|c|c|}
\hline Quantile & 0.02 & 0.04 & 0.06 & 0.08 & 0.10 & 0.50 & 0.90 & 0.92 & 0.94 & 0.96 & 0.98 \\
\hline US as Origin & & & & & & & & & & & \\
\hline UK & -1.435 & -1.476 & -0.889 & -0.969 & -1.246 & -0.507 & $-0.673^{*}$ & $-0.861 *$ & $-1.006^{*}$ & $-1.229^{*}$ & $-1.507^{*}$ \\
\hline Germany & 0.033 & 0.238 & -0.949 & -0.807 & $-1.204^{*}$ & $-0.891 * *$ & $-0.774 *$ & $-0.896^{*}$ & -1.030 & $-1.773^{* *}$ & -1.315 \\
\hline France & -1.435 & -0.123 & -0.835 & -0.956 & $-1.333^{*}$ & $-0.581^{*}$ & -0.739 & $-1.011 *$ & -0.983 & $-1.796 * *$ & -1.341 \\
\hline Japan & -0.707 & -1.028 & -0.732 & -0.647 & -0.536 & $-0.725^{* *}$ & $-0.671^{*}$ & -0.592 & $-0.739^{*}$ & $-0.902^{*}$ & -1.093 \\
\hline Argentina & -0.849 & -0.207 & -1.023 & -1.058 & -1.258 & $-1.123 * *$ & $-0.784 *$ & -0.669 & $-1.340^{*}$ & -1.376 & -1.292 \\
\hline Brazil & -1.435 & -0.270 & -1.258 & -1.093 & -1.385 & -0.401 & -0.775 & -0.711 & -1.131 & -0.665 & -0.550 \\
\hline Chile & -0.818 & -0.846 & -1.647 & -1.619 & -1.518 & $-0.899 * *$ & -0.730 & -0.853 & -1.061 & -1.215 & -1.273 \\
\hline Mexico & -1.446 & -0.438 & -1.213 & $-1.600 * *$ & $-1.444^{*}$ & $-0.837^{* *}$ & -0.496 & -0.866 & $-1.283^{*}$ & $-1.402 *$ & -0.858 \\
\hline Hong Kong & -1.161 & $-2.600 * *$ & $-1.976^{* *}$ & $-1.704 * *$ & $-1.400^{*}$ & $-0.973 * *$ & -0.261 & -0.243 & -0.375 & -0.613 & -0.168 \\
\hline Indonesia & -1.648 & $-2.194 *$ & $-2.240^{*}$ & -1.913 & $-2.118^{*}$ & $-0.746^{*}$ & -0.385 & -0.443 & -0.163 & -0.277 & -0.581 \\
\hline Korea & 0.721 & -0.800 & -1.097 & -0.909 & -1.326 & $-1.153^{* *}$ & $-0.948 * *$ & -0.804 & -0.890 & -1.100 & 0.133 \\
\hline Malaysia & $-1.570^{*}$ & -1.465 & $-1.962 * *$ & $-1.845^{* *}$ & $-1.809 * *$ & $-0.764 * *$ & -0.440 & -0.325 & -0.161 & -0.241 & -0.263 \\
\hline The Phillipines & $-2.106^{*}$ & $-2.078^{*}$ & -1.394 & $-1.619^{*}$ & $-1.765^{* *}$ & $-0.629 * *$ & -0.483 & -0.484 & -0.627 & $-1.462^{*}$ & $-1.665^{* *}$ \\
\hline Singapore & -0.476 & -1.599 & -0.769 & -0.839 & -1.413 & $-0.829 * *$ & -0.541 & -0.702 & -0.962 & $-1.221^{*}$ & $-2.042 * *$ \\
\hline Taiwan & -1.052 & $-2.448 *$ & $-2.764 * *$ & $-2.284^{* *}$ & $-2.180 * *$ & -0.583 & -0.258 & -0.235 & -0.240 & -0.896 & -0.869 \\
\hline Thailand & -1.580 & -1.459 & -1.073 & -0.674 & -1.197 & $-0.918^{* *}$ & -0.667 & -0.758 & $-1.136^{* *}$ & $-1.386^{* *}$ & $-1.364 * *$ \\
\hline \multicolumn{12}{|l|}{ UK as Origin } \\
\hline US & -1.861 & -2.246 & -0.924 & -0.810 & -1.279 & $-0.824^{*}$ & $-1.089 * *$ & -0.459 & -0.434 & -0.586 & -0.674 \\
\hline Germany & -0.599 & -1.161 & -1.011 & $-1.741^{*}$ & -1.557 & -0.676 & -0.609 & -0.129 & 0.599 & 0.057 & -0.071 \\
\hline France & -2.377 & $-3.060^{*}$ & -2.057 & -1.872 & $-2.561^{* *}$ & -0.439 & -0.318 & -0.285 & 0.680 & 0.535 & 0.511 \\
\hline Japan & -2.695 & -2.509 & $-2.263^{* *}$ & $-1.757^{*}$ & $-1.667 * *$ & -0.694 & 0.418 & 0.461 & 0.349 & 0.205 & 1.387 \\
\hline Argentina & -0.496 & -2.439 & $-2.184^{*}$ & $-2.649^{* *}$ & $-3.301 * *$ & $-1.528^{*}$ & -1.166 & -1.212 & -0.163 & 0.489 & 0.703 \\
\hline Brazil & -2.593 & $-2.866 * *$ & $-2.035^{* *}$ & $-1.935^{* *}$ & $-2.624 * *$ & -0.404 & -0.997 & -0.640 & 1.037 & 0.827 & 0.488 \\
\hline Chile & -2.417 & -3.166 & $-2.380^{*}$ & $-2.117^{* *}$ & $-2.478 * *$ & -0.800 & -0.535 & -0.679 & -0.359 & 0.923 & 0.726 \\
\hline Mexico & -3.977 & -2.602 & -1.548 & -1.945 & -1.773 & $-1.235^{* *}$ & -0.419 & -0.446 & -0.442 & -0.550 & -0.476 \\
\hline Hong Kong & -2.357 & $-2.976^{*}$ & $-2.807 * *$ & $-2.786^{* *}$ & $-2.774 * *$ & -0.768 & 0.228 & 0.039 & 0.107 & 1.725 & 0.100 \\
\hline Indonesia & -2.293 & -2.666 & $-3.301 * *$ & $-3.701^{* *}$ & $-4.210^{* *}$ & -0.612 & 1.017 & 0.768 & 0.089 & 0.898 & 0.279 \\
\hline Korea & -1.589 & -1.760 & $-1.884^{* *}$ & $-2.514^{* *}$ & $-2.610^{* *}$ & $-1.921 * *$ & -0.130 & -0.403 & -0.547 & 0.507 & 0.336 \\
\hline Malaysia & $-2.016^{* *}$ & $-3.058 * *$ & $-3.217 * *$ & $-3.363^{* *}$ & $-2.530 * *$ & -0.721 & 0.540 & 0.648 & 0.524 & 1.340 & -0.417 \\
\hline The Phillipines & -2.746 & $-3.990 * *$ & $-3.712 * *$ & $-3.999 * *$ & $-4.205^{* *}$ & $-1.235^{* *}$ & 0.188 & 0.666 & 0.905 & 1.016 & 0.876 \\
\hline Singapore & -1.906 & -2.184 & $-2.688 * *$ & $-2.963^{* *}$ & $-2.465^{* *}$ & -0.629 & -0.003 & -0.125 & -0.604 & -0.639 & -0.301 \\
\hline Taiwan & -1.421 & -2.309 & $-3.237^{* *}$ & $-3.663^{* *}$ & $-3.689 * *$ & $-1.441^{* *}$ & 0.336 & 1.287 & $2.145^{*}$ & 1.686 & 1.662 \\
\hline Thailand & -2.667 & -2.590 & $-3.156^{* *}$ & $-3.278^{* *}$ & $-2.258^{* *}$ & -0.617 & -1.213 & -0.237 & -0.123 & 0.885 & 0.276 \\
\hline
\end{tabular}

The symbols * and ** indicate statistical significance at $10 \%$ and $5 \%$ respectively. 
Table 8: Quantile regression estimates for VIX

\begin{tabular}{|c|c|c|c|c|c|c|c|c|c|c|c|}
\hline Quantile & 0.02 & 0.04 & 0.06 & 0.08 & 0.10 & 0.50 & 0.90 & 0.92 & 0.94 & 0.96 & 0.98 \\
\hline US as Origin & & & & & & & & & & & \\
\hline UK & 0.003 & -0.008 & 0.001 & -0.004 & 0.003 & $-0.012 * *$ & $-0.016^{* *}$ & $-0.018^{* *}$ & $-0.025^{* *}$ & $-0.026^{*}$ & -0.029 \\
\hline Germany & 0.003 & -0.008 & -0.013 & 0.001 & 0.002 & $-0.012^{* *}$ & $-0.023^{* *}$ & $-0.023 * *$ & $-0.028 * *$ & $-0.029 *$ & $-0.046^{*}$ \\
\hline France & 0.003 & -0.002 & -0.005 & 0.004 & 0.005 & -0.009 & $-0.024 * *$ & $-0.028 * *$ & $-0.029 * *$ & $-0.029 *$ & $-0.046^{*}$ \\
\hline Japan & -0.006 & -0.016 & -0.014 & 0.002 & 0.000 & -0.009 & -0.007 & -0.005 & -0.008 & -0.012 & $-0.024 *$ \\
\hline Argentina & 0.004 & -0.006 & 0.000 & -0.008 & -0.005 & $-0.016^{* *}$ & $-0.019^{* *}$ & $-0.020 * *$ & $-0.027 * *$ & $-0.036^{* *}$ & $-0.046^{*}$ \\
\hline Brazil & 0.003 & 0.000 & -0.007 & -0.006 & -0.004 & -0.001 & -0.009 & -0.007 & -0.021 & -0.020 & -0.022 \\
\hline Chile & 0.007 & -0.008 & 0.008 & 0.007 & -0.003 & -0.011 & $-0.016^{*}$ & -0.016 & -0.027 & -0.027 & -0.029 \\
\hline Mexico & 0.001 & -0.008 & -0.007 & 0.002 & 0.004 & $-0.011^{*}$ & -0.002 & -0.009 & $-0.026^{*}$ & -0.025 & 0.012 \\
\hline Hong Kong & 0.010 & 0.005 & 0.006 & 0.003 & 0.001 & $-0.014 * *$ & $-0.018^{* *}$ & $-0.018^{* *}$ & $-0.022 * *$ & $-0.028^{*}$ & -0.013 \\
\hline Indonesia & -0.008 & -0.016 & -0.010 & -0.022 & -0.010 & $-0.018^{* *}$ & $-0.020^{* *}$ & $-0.017 * *$ & $-0.021 * *$ & $-0.031 * *$ & $-0.036^{* *}$ \\
\hline Korea & -0.005 & -0.008 & -0.011 & -0.012 & -0.002 & $-0.016^{* *}$ & $-0.019 * *$ & $-0.020^{* *}$ & $-0.027 * *$ & -0.025 & -0.007 \\
\hline Malaysia & 0.019 & 0.011 & 0.005 & -0.003 & -0.002 & $-0.011^{* *}$ & $-0.019 * *$ & $-0.022 * *$ & $-0.017 *$ & -0.013 & -0.025 \\
\hline The Phillipines & -0.010 & -0.025 & -0.013 & -0.003 & -0.008 & -0.010 & $-0.012 *$ & -0.008 & $-0.017 *$ & $-0.036 * *$ & $-0.045^{* *}$ \\
\hline Singapore & -0.003 & -0.003 & -0.009 & -0.004 & -0.005 & $-0.012 * *$ & $-0.020^{* *}$ & $-0.026^{* *}$ & $-0.029 * *$ & $-0.036^{* *}$ & -0.036 \\
\hline Taiwan & 0.007 & -0.012 & -0.005 & -0.013 & -0.003 & -0.008 & -0.008 & -0.012 & -0.010 & -0.022 & -0.003 \\
\hline Thailand & -0.006 & -0.022 & 0.001 & 0.002 & 0.001 & $-0.017^{* *}$ & -0.011 & $-0.017 * *$ & $-0.020^{*}$ & $-0.029 *$ & -0.030 \\
\hline \multicolumn{12}{|l|}{ UK as Origin } \\
\hline US & -0.106 & -0.016 & -0.011 & 0.004 & 0.000 & -0.008 & $-0.012 * *$ & $-0.012 * *$ & -0.010 & -0.016 & 0.008 \\
\hline Germany & -0.023 & -0.006 & 0.001 & -0.005 & -0.012 & -0.009 & 0.004 & -0.001 & 0.000 & -0.013 & 0.000 \\
\hline France & -0.019 & 0.001 & 0.002 & -0.003 & -0.013 & -0.005 & 0.005 & 0.000 & -0.006 & -0.008 & -0.011 \\
\hline Japan & -0.003 & -0.014 & $-0.015^{*}$ & -0.014 & -0.008 & -0.004 & $0.012 * *$ & $0.010^{*}$ & $0.011^{*}$ & 0.006 & 0.011 \\
\hline Argentina & 0.011 & -0.021 & 0.001 & -0.009 & -0.012 & $-0.014^{*}$ & 0.006 & 0.008 & 0.005 & -0.015 & -0.003 \\
\hline Brazil & -0.022 & -0.027 & 0.002 & -0.002 & -0.006 & -0.002 & 0.008 & 0.008 & 0.001 & 0.001 & -0.001 \\
\hline Chile & -0.015 & -0.033 & -0.012 & -0.013 & -0.011 & -0.006 & -0.007 & -0.005 & 0.006 & -0.003 & 0.005 \\
\hline Mexico & -0.022 & -0.023 & -0.010 & -0.007 & -0.008 & -0.006 & 0.008 & 0.017 & 0.013 & 0.005 & 0.006 \\
\hline Hong Kong & -0.010 & -0.006 & -0.011 & -0.007 & -0.012 & -0.009 & -0.007 & -0.004 & -0.004 & -0.001 & -0.021 \\
\hline Indonesia & -0.018 & -0.024 & -0.009 & -0.014 & -0.015 & -0.010 & -0.005 & -0.004 & -0.008 & -0.008 & -0.010 \\
\hline Korea & -0.007 & -0.021 & -0.019 & -0.012 & -0.013 & $-0.012 *$ & 0.013 & 0.009 & 0.008 & 0.003 & -0.011 \\
\hline Malaysia & 0.002 & -0.012 & -0.012 & -0.013 & -0.013 & -0.008 & -0.004 & -0.006 & 0.010 & 0.004 & 0.009 \\
\hline The Phillipines & -0.002 & -0.011 & -0.017 & $-0.019^{*}$ & $-0.021 * *$ & -0.006 & 0.002 & -0.002 & -0.005 & -0.014 & -0.008 \\
\hline Singapore & -0.035 & 0.001 & -0.016 & -0.011 & -0.013 & -0.008 & -0.006 & 0.002 & 0.005 & -0.005 & 0.001 \\
\hline Taiwan & -0.012 & -0.005 & -0.020 & -0.022 & -0.013 & -0.011 & 0.000 & -0.005 & -0.004 & -0.005 & 0.016 \\
\hline Thailand & -0.014 & 0.001 & -0.007 & -0.011 & -0.010 & -0.011 & -0.001 & -0.006 & -0.008 & -0.009 & -0.025 \\
\hline
\end{tabular}

The symbols * and $* *$ indicate statistical significance at $10 \%$ and $5 \%$ respectively. 
Table 9: Quantile regression estimates for the conditional volatility

\begin{tabular}{|c|c|c|c|c|c|c|c|c|c|c|c|}
\hline Quantile & 0.02 & 0.04 & 0.06 & 0.08 & 0.10 & 0.50 & 0.90 & 0.92 & 0.94 & 0.96 & 0.98 \\
\hline US as Origin & & & & & & & & & & & \\
\hline UK & -1.883 & -1.228 & $-1.607 * *$ & $-1.599 * *$ & $-1.117 * *$ & -0.036 & $0.819^{* *}$ & $0.817 * *$ & $0.819^{* *}$ & $1.120^{* *}$ & $1.359^{* *}$ \\
\hline Germany & -1.883 & -1.584 & $-1.543 * *$ & $-1.248 * *$ & $-1.131 * *$ & -0.010 & $0.774 * *$ & $0.759 * *$ & $0.745^{* *}$ & $0.816^{* *}$ & 0.673 \\
\hline France & -1.883 & -1.479 & $-1.563 * *$ & $-1.164^{*}$ & $-0.971^{*}$ & 0.005 & $0.678^{* *}$ & $0.661 * *$ & $0.816^{* *}$ & $0.874 * *$ & 0.774 \\
\hline Japan & -0.954 & -1.013 & -0.729 & $-0.955^{* *}$ & $-1.005^{* *}$ & -0.132 & $0.669 * *$ & $0.746^{* *}$ & $0.815^{* *}$ & $0.779 * *$ & 0.659 \\
\hline Argentina & $-3.619 * *$ & -1.517 & $-1.284 *$ & $-1.214 * *$ & $-1.131 * *$ & $-0.312^{*}$ & $0.695^{* *}$ & $0.538 * *$ & $0.678^{* *}$ & 0.563 & 0.587 \\
\hline Brazil & -1.883 & -1.436 & $-1.446^{*}$ & $-1.118^{*}$ & $-1.146^{* *}$ & 0.167 & $1.144 * *$ & $1.401^{* *}$ & $1.379^{* *}$ & $1.490^{* *}$ & $1.282 * *$ \\
\hline Chile & $-3.003 * *$ & -0.640 & -0.719 & -0.730 & -0.674 & 0.076 & $0.774 * *$ & $0.783^{* *}$ & $0.676^{*}$ & $1.341^{* *}$ & $1.263^{* *}$ \\
\hline Mexico & $-2.271^{*}$ & -1.443 & $-1.456^{* *}$ & $-1.012 *$ & $-0.887^{*}$ & -0.099 & $1.023 * *$ & $1.066^{* *}$ & $1.053^{* *}$ & $1.469^{* *}$ & $1.998 * *$ \\
\hline Hong Kong & -1.675 & -0.528 & -0.749 & $-0.796^{*}$ & $-0.842 * *$ & 0.036 & $0.508^{* *}$ & $0.493^{* *}$ & $0.493 *$ & 0.410 & $1.300^{*}$ \\
\hline Indonesia & $-3.393 * *$ & -0.930 & -1.082 & $-1.217^{*}$ & -0.546 & -0.001 & $0.526^{* *}$ & $0.481 * *$ & 0.419 & 0.281 & 0.241 \\
\hline Korea & $-2.856^{* *}$ & -1.368 & $-1.503^{* *}$ & $-1.351 * *$ & $-1.059^{*}$ & -0.053 & $0.768 * *$ & $0.700^{* *}$ & $0.636^{* *}$ & $0.927^{*}$ & $1.487 * *$ \\
\hline Malaysia & $-0.800 *$ & $-0.736^{* *}$ & $-0.740 *$ & -0.407 & -0.443 & -0.105 & $0.318^{* *}$ & $0.289^{*}$ & $0.461 * *$ & $0.453^{*}$ & 0.427 \\
\hline The Phillipines & $-2.248 * *$ & -0.882 & -0.373 & -0.467 & -0.265 & -0.016 & $0.480^{* *}$ & $0.583^{* *}$ & $0.577 * *$ & $0.626^{*}$ & 0.580 \\
\hline Singapore & $-3.045^{*}$ & -0.954 & -0.707 & -0.750 & -0.608 & 0.027 & $0.691 * *$ & $0.661 * *$ & 0.63 & 0.576 & 0.576 \\
\hline Taiwan & $-2.425 * *$ & -0.570 & -0.671 & -0.817 & -0.630 & -0.030 & $0.555^{* *}$ & $0.466^{* *}$ & $0.643 * *$ & 0.714 & $1.555^{* *}$ \\
\hline Thailand & $-3.176^{* *}$ & -0.980 & -1.055 & $-0.872^{*}$ & -0.590 & 0.067 & $0.727^{* *}$ & $0.708^{* *}$ & $0.720^{* *}$ & $0.640^{* *}$ & 0.748 \\
\hline \multicolumn{12}{|l|}{ UK as Origin } \\
\hline US & -0.212 & $-0.974 *$ & $-1.334 * *$ & $-1.233^{* *}$ & -0.673 & 0.261 & $1.112 * *$ & $1.101 * *$ & $1.147^{* *}$ & $1.060^{* *}$ & $1.939 * *$ \\
\hline Germany & $-2.319^{*}$ & $-1.845^{* *}$ & $-1.961 * *$ & $-1.335^{*}$ & $-1.309^{*}$ & 0.352 & $1.434 * *$ & $1.528 * *$ & $1.621^{* *}$ & $1.872^{* *}$ & $1.931^{* *}$ \\
\hline France & -1.613 & $-1.471 * *$ & $-1.703^{* *}$ & $-1.234 *$ & -1.038 & 0.274 & $1.765^{* *}$ & $1.685^{* *}$ & $1.567^{* *}$ & $1.525^{* *}$ & $1.623^{* *}$ \\
\hline Japan & -0.115 & -0.415 & $-0.544 *$ & $-0.629 * *$ & $-0.559 *$ & 0.014 & $0.779 * *$ & $0.797 * *$ & $0.971 * *$ & $0.947^{* *}$ & 0.754 \\
\hline Argentina & -0.675 & -0.470 & $-0.772 *$ & $-0.792 * *$ & $-0.761 * *$ & -0.013 & $1.640 * *$ & $1.655^{* *}$ & $1.555^{* *}$ & $0.929 * *$ & $1.133 * *$ \\
\hline Brazil & -1.590 & $-1.338^{* *}$ & $-1.757^{* *}$ & -1.064 & -0.883 & $0.566^{* *}$ & $1.763 * *$ & $1.841 * *$ & $1.647 * *$ & $1.436^{* *}$ & $1.469 * *$ \\
\hline Chile & -0.017 & 0.034 & -0.367 & -0.523 & -0.548 & $0.416^{*}$ & $1.323 * *$ & $1.495 * *$ & $1.434 * *$ & $1.194 * *$ & $1.310^{*}$ \\
\hline Mexico & -1.086 & -0.910 & $-1.344 * *$ & $-1.392 * *$ & $-1.308^{*}$ & $0.539 *$ & $1.297 * *$ & $1.518^{* *}$ & $1.449 * *$ & $1.373^{* *}$ & $1.888^{* *}$ \\
\hline Hong Kong & -0.356 & -0.487 & $-0.774 * *$ & -0.443 & $-0.497 *$ & 0.097 & $0.813 * *$ & $0.880 * *$ & $0.756^{*}$ & 0.682 & 1.001 \\
\hline Indonesia & -0.511 & -0.471 & $-0.695^{*}$ & -0.465 & -0.457 & 0.243 & $0.765^{*}$ & $0.960 * *$ & $1.411^{* *}$ & $1.286^{* *}$ & $1.547^{* *}$ \\
\hline Korea & -1.229 & $-1.263^{* *}$ & $-1.301 * *$ & $-1.200 * *$ & $-0.946^{* *}$ & 0.237 & $1.018^{* *}$ & $1.211 * *$ & $1.163^{* *}$ & $0.956^{* *}$ & $1.041^{* *}$ \\
\hline Malaysia & -0.216 & -0.102 & -0.340 & -0.111 & -0.322 & 0.125 & $0.786^{* *}$ & $0.747 * *$ & $0.770^{*}$ & 0.592 & $1.260^{* *}$ \\
\hline The Phillipines & -0.350 & -0.232 & -0.358 & -0.377 & -0.374 & 0.080 & $0.948^{* *}$ & 0.827 & $1.129 * *$ & $0.947^{*}$ & $1.273 *$ \\
\hline Singapore & -0.374 & -0.764 & $-0.715^{*}$ & -0.450 & -0.282 & 0.173 & $0.981 * *$ & $1.011 * *$ & $1.155^{* *}$ & $1.314 * *$ & $1.156^{* *}$ \\
\hline Taiwan & -0.392 & -0.441 & -0.398 & -0.400 & $-0.481 * *$ & 0.265 & $0.779 * *$ & 0.582 & 0.616 & 0.723 & $1.396^{* *}$ \\
\hline Thailand & -0.311 & -0.034 & -0.062 & -0.040 & -0.107 & 0.275 & $1.273 * *$ & $1.360 * *$ & $1.044 * *$ & $1.023 * *$ & $0.933^{*}$ \\
\hline
\end{tabular}

The symbols $*$ and $* *$ indicate statistical significance at $10 \%$ and $5 \%$ respectively. 
Table 10: The goodness-of-fit (R-squared) measures of the quantile regression models

\begin{tabular}{|c|c|c|c|c|c|c|c|c|c|c|c|}
\hline Quantile & 0.02 & 0.04 & 0.06 & 0.08 & 0.10 & 0.50 & 0.90 & 0.92 & 0.94 & 0.96 & 0.98 \\
\hline US as Origin & & & & & & & & & & & \\
\hline UK & 0.17 & 0.14 & 0.10 & 0.08 & 0.08 & 0.02 & 0.14 & 0.14 & 0.15 & 0.17 & 0.22 \\
\hline Germany & 0.17 & 0.10 & 0.07 & 0.05 & 0.04 & 0.02 & 0.13 & 0.13 & 0.13 & 0.15 & 0.18 \\
\hline France & 0.15 & 0.10 & 0.05 & 0.04 & 0.04 & 0.02 & 0.11 & 0.12 & 0.12 & 0.15 & 0.18 \\
\hline Japan & 0.16 & 0.17 & 0.15 & 0.13 & 0.13 & 0.11 & 0.11 & 0.11 & 0.12 & 0.12 & 0.10 \\
\hline Argentina & 0.20 & 0.15 & 0.12 & 0.11 & 0.10 & 0.04 & 0.09 & 0.09 & 0.09 & 0.10 & 0.15 \\
\hline Brazil & 0.19 & 0.14 & 0.09 & 0.06 & 0.05 & 0.01 & 0.14 & 0.15 & 0.16 & 0.20 & 0.27 \\
\hline Chile & 0.13 & 0.09 & 0.06 & 0.04 & 0.03 & 0.01 & 0.12 & 0.12 & 0.12 & 0.15 & 0.15 \\
\hline Mexico & 0.20 & 0.14 & 0.10 & 0.06 & 0.05 & 0.02 & 0.12 & 0.13 & 0.14 & 0.18 & 0.21 \\
\hline Hong Kong & 0.17 & 0.14 & 0.11 & 0.10 & 0.08 & 0.03 & 0.10 & 0.09 & 0.09 & 0.08 & 0.09 \\
\hline Indonesia & 0.29 & 0.18 & 0.12 & 0.09 & 0.08 & 0.02 & 0.08 & 0.08 & 0.08 & 0.08 & 0.10 \\
\hline Korea & 0.23 & 0.17 & 0.12 & 0.09 & 0.07 & 0.03 & 0.12 & 0.12 & 0.11 & 0.11 & 0.13 \\
\hline Malaysia & 0.16 & 0.12 & 0.09 & 0.09 & 0.09 & 0.03 & 0.08 & 0.08 & 0.08 & 0.06 & 0.01 \\
\hline The Phillipines & 0.20 & 0.10 & 0.08 & 0.07 & 0.07 & 0.02 & 0.09 & 0.08 & 0.08 & 0.08 & 0.14 \\
\hline Singapore & 0.10 & 0.09 & 0.09 & 0.08 & 0.07 & 0.02 & 0.12 & 0.11 & 0.11 & 0.12 & 0.12 \\
\hline Taiwan & 0.19 & 0.17 & 0.13 & 0.11 & 0.10 & 0.02 & 0.06 & 0.07 & 0.09 & 0.10 & 0.15 \\
\hline Thailand & 0.17 & 0.11 & 0.11 & 0.09 & 0.08 & 0.03 & 0.10 & 0.10 & 0.11 & 0.11 & 0.09 \\
\hline \multicolumn{12}{|l|}{ UK as Origin } \\
\hline US & 0.15 & 0.13 & 0.11 & 0.09 & 0.09 & 0.02 & 0.15 & 0.17 & 0.19 & 0.21 & 0.27 \\
\hline Germany & 0.19 & 0.15 & 0.10 & 0.07 & 0.06 & 0.01 & 0.12 & 0.15 & 0.17 & 0.20 & 0.24 \\
\hline France & 0.17 & 0.14 & 0.12 & 0.10 & 0.08 & 0.01 & 0.14 & 0.16 & 0.17 & 0.19 & 0.22 \\
\hline Japan & 0.14 & 0.18 & 0.17 & 0.15 & 0.14 & 0.01 & 0.10 & 0.12 & 0.14 & 0.17 & 0.22 \\
\hline Argentina & 0.07 & 0.11 & 0.12 & 0.11 & 0.11 & 0.02 & 0.12 & 0.14 & 0.16 & 0.17 & 0.19 \\
\hline Brazil & 0.22 & 0.17 & 0.14 & 0.11 & 0.09 & 0.02 & 0.19 & 0.21 & 0.21 & 0.22 & 0.22 \\
\hline Chile & 0.09 & 0.11 & 0.09 & 0.09 & 0.09 & 0.02 & 0.12 & 0.14 & 0.16 & 0.16 & 0.14 \\
\hline Mexico & 0.19 & 0.15 & 0.11 & 0.09 & 0.06 & 0.02 & 0.09 & 0.11 & 0.15 & 0.17 & 0.17 \\
\hline Hong Kong & 0.17 & 0.17 & 0.15 & 0.13 & 0.12 & 0.01 & 0.11 & 0.12 & 0.12 & 0.15 & 0.16 \\
\hline Indonesia & 0.21 & 0.18 & 0.17 & 0.17 & 0.16 & 0.02 & 0.10 & 0.11 & 0.14 & 0.19 & 0.19 \\
\hline Korea & 0.25 & 0.23 & 0.19 & 0.16 & 0.14 & 0.03 & 0.09 & 0.11 & 0.13 & 0.16 & 0.21 \\
\hline Malaysia & 0.18 & 0.18 & 0.17 & 0.16 & 0.15 & 0.02 & 0.09 & 0.09 & 0.10 & 0.13 & 0.16 \\
\hline The Phillipines & 0.25 & 0.23 & 0.21 & 0.19 & 0.16 & 0.01 & 0.08 & 0.10 & 0.12 & 0.17 & 0.22 \\
\hline Singapore & 0.11 & 0.12 & 0.11 & 0.10 & 0.09 & 0.01 & 0.10 & 0.10 & 0.10 & 0.12 & 0.17 \\
\hline Taiwan & 0.12 & 0.17 & 0.20 & 0.19 & 0.18 & 0.02 & 0.10 & 0.12 & 0.13 & 0.17 & 0.18 \\
\hline Thailand & 0.13 & 0.12 & 0.11 & 0.10 & 0.10 & 0.02 & 0.07 & 0.08 & 0.11 & 0.13 & 0.15 \\
\hline
\end{tabular}


Table 11: Tests of equality of slope parameters

\begin{tabular}{l|ccc|ccc}
\hline \hline & \multicolumn{3}{|c|}{ UK } & & US & \\
\cline { 2 - 7 } & Dummy & VIX & Volatility & Dummy & VIX & Volatility \\
\hline US & -0.190 & 0.011 & $-1.785^{* *}$ & & & \\
UK & & & & -0.573 & 0.019 & -1.936 \\
Germany & -0.948 & -0.015 & $-2.743^{* *}$ & -0.431 & $0.025^{* *}$ & $-1.905^{* *}$ \\
France & $-2.244^{*}$ & -0.018 & $-2.804^{* *}$ & -0.594 & $0.030^{* *}$ & $-1.650^{*}$ \\
Japan & $-2.086^{* *}$ & $-0.021^{* *}$ & $-1.338^{* *}$ & 0.135 & 0.007 & $-1.674^{* *}$ \\
Argentina & $-2.135^{* *}$ & -0.018 & $-2.401^{* *}$ & -0.474 & 0.014 & $-1.826^{* *}$ \\
Brazil & $-1.627^{*}$ & -0.015 & $-2.646^{* *}$ & -0.609 & 0.005 & $-2.290^{* *}$ \\
Chile & $-1.943^{* *}$ & -0.004 & $-1.871^{* *}$ & -0.787 & 0.013 & $-1.448^{* *}$ \\
Mexico & -1.354 & -0.016 & $-2.605^{* *}$ & -0.949 & 0.006 & $-1.910^{* *}$ \\
Hong Kong & $-3.029^{* *}$ & -0.005 & $-1.310^{* *}$ & -1.139 & $0.019^{*}$ & $-1.350^{* *}$ \\
Indonesia & $-5.227^{* *}$ & -0.010 & $-1.223^{* *}$ & -1.827 & 0.010 & -1.072 \\
Korea & $-2.479^{* *}$ & $-0.026^{*}$ & $-1.964^{* *}$ & -0.378 & 0.016 & $-1.827^{* *}$ \\
Malaysia & $-3.070^{* *}$ & -0.009 & $-1.108^{* *}$ & $-1.369 * *$ & $0.018^{*}$ & $-0.761^{* *}$ \\
The Phillipines & $-4.393^{* *}$ & $-0.023^{* *}$ & $-1.322^{* *}$ & $-1.282^{*}$ & 0.004 & $-0.745^{* *}$ \\
Singapore & $-2.460^{* *}$ & -0.007 & $-1.263^{* *}$ & -0.872 & 0.015 & $-1.299^{* *}$ \\
Taiwan & $-4.025^{* *}$ & -0.013 & $-1.259^{* *}$ & $-2.486^{*}$ & 0.005 & -1.185 \\
Thailand & -1.045 & -0.008 & $-1.380^{* *}$ & -0.529 & 0.012 & $-1.317^{* *}$ \\
\hline
\end{tabular}

The symbols $*$ and $* *$ indicate statistical significance at $10 \%$ and $5 \%$ respectively. 